\title{
Early Social Isolation Stress and Perinatal NMDA Receptor Antagonist Treatment Induce Changes in the Structure and Neurochemistry of Inhibitory Neurons of the Adult Amygdala and Prefrontal Cortex
}

\author{
(D)Esther Castillo-Gómez, ${ }^{1, *}$ (D) Marta Pérez-Rando, ${ }^{1, *}$ María Bellés, ${ }^{1}$ Javier Gilabert-Juan, ${ }^{1,2,3,4}$ \\ José Vicente Llorens, ${ }^{2}{ }^{1}$ Héctor Carceller, ${ }^{1}$ Clara Bueno-Fernández, ${ }^{1}$ @Clara García-Mompó, ${ }^{1}$ \\ Beatriz Ripoll-Martínez, ${ }^{1}$ Yasmina Curto, ${ }^{1}$ Noelia Sebastiá-Ortega, ${ }^{2,3}$ @ María Dolores Moltó, ${ }^{2,3,4}$ \\ Julio Sanjuan, ${ }^{3,4}$ and (D) Juan Nacher ${ }^{1,3,4}$
}

\section{DOI:http://dx.doi.org/10.1523/ENEURO.0034-17.2017}

\begin{abstract}
${ }^{1}$ Neurobiology Unit, Cell Biology Department, Interdisciplinary Research Structure for Biotechnology and Biomedicine (BIOTECMED), Universitat De València, Burjassot 46100, Spain, ${ }^{2}$ Department of Genetics, Universitat De València, Burjassot 46100, Spain, ${ }^{3} \mathrm{CIBERSAM:} \mathrm{Spanish} \mathrm{National} \mathrm{Network} \mathrm{for} \mathrm{Research} \mathrm{in} \mathrm{Mental} \mathrm{Health,} 28029$ Madrid, and ${ }^{4}$ Fundación Investigación Hospital Clínico De Valencia, INCLIVA, Valencia 46010, Spain
\end{abstract}

\begin{abstract}
The exposure to aversive experiences during early life influences brain development and leads to altered behavior. Moreover, the combination of these experiences with subtle alterations in neurodevelopment may contribute to the emergence of psychiatric disorders, such as schizophrenia. Recent hypotheses suggest that imbalances between excitatory and inhibitory (E/I) neurotransmission, especially in the prefrontal cortex and the amygdala, may underlie their etiopathology. In order to understand better the neurobiological bases of these alterations, we studied the impact of altered neurodevelopment and chronic early-life stress on these two brain regions. Transgenic mice displaying fluorescent excitatory and inhibitory neurons, received a single injection of MK801 (NMDAR antagonist) or vehicle solution at postnatal day 7 and/or were socially isolated from the age of weaning until adulthood (3 months old). We found that anxiety-related behavior, brain volume, neuronal structure, and the expression of molecules related to plasticity and E/I neurotransmission in adult mice were importantly affected by early-life stress. Interestingly, many of these effects were potentiated when the stress paradigm was applied to mice perinatally injected with MK801 ("double-hit" model). These results clearly show the impact of early-life stress on the adult brain, especially on the structure and plasticity of inhibitory networks, and highlight the double-hit model as a valuable tool to study the contribution of early-life stress in the emergence of neurodevelopmental psychiatric disorders, such as schizophrenia.
\end{abstract}

Key words: interneuron; neuronal plasticity; PSA-NCAM; schizophrenia; social isolation; stress

\section{Significance Statement}

The double-hit model constitutes a valuable tool for future experiments exploring the effects of aversive experiences during early life and the biological basis of mental disorders, such as schizophrenia. It also supports the emerging hypothesis of altered $\mathrm{E} / \mathrm{I}$ balance in key brain regions as one of the underlying causes of the disease. Our study also supports the idea that such imbalances may arise from problems in initial neural circuit formation or its maintenance, because we found alterations in the structure of inhibitory circuits and also in the expression of molecules related to their plasticity and maturation. 


\section{Introduction}

Aversive experiences, such as chronic stress, remodel the structure and connectivity of excitatory and inhibitory excitatory and inhibitory (E/I) neurons. These effects of stress are particularly relevant during early life and may constitute a predisposing factor for the development of psychiatric disorders, such as schizophrenia. In fact, patients show important alterations in different brain regions, including the prefrontal cortex (PFC) and the amygdala (Goghari et al. 2010). Interestingly, the structure of E/I neurons in these two regions is dramatically affected by stress (Gilabert-Juan et al. 2011, 2013b; Duman and Duman, 2015).

Different animal models have been generated to understand the impact of early-life stress on the structure of the adult brain and its influence on schizophrenia and other psychiatric disorders. The post-weaning social isolation paradigm is one of these models and reproduces some of the behavioral, structural, and neurochemical alterations found in schizophrenic patients (Geyer et al. 1993; Ferdman et al. 2007; Gilabert-Juan et al. 2012; Wang et al. 2012; Glausier and Lewis, 2013). Given the importance of altered neurodevelopment on the etiology of schizophrenia and other mental disorders, this paradigm has been lately combined with experimental interventions during early postnatal life, such as the administration of NMDA receptor (NMDAR) antagonists (i.e., MK801), which alters the latest stages of neocortical development (Hickey et al. 2012; Lim et al. 2012; Gilabert-Juan et al. 2013a). Numerous studies in humans and animal models of schizophrenia, have documented the presence of structural alterations in the basolateral amygdala (BLA) and PFC, including volume loss in both regions (Jaaro-Peled et al. 2010; Levitt et al. 2010; Gilabert-Juan et al. 2013a). These volumetric alterations may probably reflect structural changes in PFC

Received January 29, 2017; accepted March 2, 2017; First published April 21, 2017.

All authors reported no biomedical financial interests or potential conflicts of interest.

Author contributions: E.C.-G. and J.N. designed the study; E.C.-.G., M.P.-R., M.B., J.G.-J., J.V.L., H.C., C.B.-F., C.G.-M., B.R.-M., Y.C., and N.S.-O. performed the experiments; E.C.-G. and M.P.-R. analyzed the data; E.C.-G. and M.P.-R. prepared the figures; E.C.-G., M.P.-R., and J.N. wrote the paper; M.D.M. supervised the molecular part of the project; J.S. reviewed the manuscript and gave clinical advice. J.N. supervised the whole project; all authors read and approved the final paper.

This work was supported by the Spanish Ministry of Economy and Competitiveness (BFU2012-32512, SAF2015-68436-R), Generalitat Valenciana (PROMETEO2013/069) and Fundación Alicia Koplowitz (FAK2012-01). M.P.-R. and Y.C. hold pre-doctoral fellowships from the Spanish Ministry of Education (FPU12/03200, FPU13/04764) and M.B., from the University of Valencia ('Atracció de talent-VLC campus').

*E.C.-G. and M.P.-R. contributed equally to this work.

Correspondence should be addressed to either Dr. Juan Nacher or Dr. Esther Castillo-Gómez, Neurobiology Unit, Cell Biology Department, Interdisciplinary Research Structure for Biotechnology and Biomedicine (BIOTECMED), Universitat de València, Dr. Moliner, 50, Burjassot 46100, Spain. E-mail: nacher@uv.es or esther.castillo@uv.es.

DOI:http://dx.doi.org/10.1523/ENEURO.0034-17.2017

Copyright (C) 2017 Castillo-Gómez et al.

This is an open-access article distributed under the terms of the Creative Commons Attribution 4.0 International license, which permits unrestricted use, distribution and reproduction in any medium provided that the original work is properly attributed. and BLA neurons, including alterations in spine density and dendritic arborization.

The polysialylated form of the neural cell adhesion molecule (PSA-NCAM) plays a key role in structural remodeling and the connectivity of neurons in the adult brain, especially of interneurons (for review, see Bonfanti, 2006; Rutishauser, 2008; Nacher et al. 2013), which is particularly evident after chronic stress (Sandi, 2004; Nacher et al. 2013). Perineuronal nets (PNNs) also play a fundamental role in the plasticity and maturation of interneurons, particularly on those expressing parvalbumin (PV; Kinden Lensjø et al. 2017). In fact, this plasticity of inhibitory networks is crucial for brain physiology and development, which largely depend on the precise balance between $E / I$ neurotransmission (E/l balance). The $E / I$ balance is compromised by stress, both in adulthood and in early life (Saaltink and Vreugdenhil, 2014; Tzanoulinou et al. 2014; van der Kooij et al. 2014) and its disbalance may be one of the underlying causes of different neurodevelopmental psychiatric disorders, including schizophrenia (Curley and Lewis, 2012; Lewis et al. 2012; Inan et al. 2013; Lin et al. 2013; Sun et al. 2013; Morishita et al. 2015). Importantly, E/I balance can also be affected by changes in the expression of other molecules that influence the physiology and development of inhibitory circuits. This is the case of glutamic acid decarboxylase (GAD; Akbarian, 1995; Akbarian and Huang, 2006; Straub et al. 2007; Mitchell et al. 2015); brain-derived neurotrophic factor (BDNF), which promotes the maturation of inhibitory synapses (Weickert et al. 2003, 2005; Tao et al. 2014); the cannabinoid receptor 1 (CB1-R), which affects their development (Volk and Lewis, 2010; den Boon et al. 2015); and neuregulin 1 (Nrg1) and its receptor ErbB4, which play prominent roles in the synaptogenesis and plasticity of inhibitory networks (Rico and Marín, 2011).

The main objective of this work is to study the impact of early-life stress on E/I circuits in the adult amygdala and PFC, especially on neuronal structure. To combine this aversive experience with a neurodevelopmental alteration, which mimic those found in schizophrenia, we have developed a "double-hit" model in transgenic mice by combining a perinatal MK801 injection and post-weaning social isolation. We have used two transgenic strains expressing fluorescent proteins in $\mathrm{E} / \mathrm{I}$ neurons and studied in detail the structural features of these neurons, the expression of molecules related to plasticity and E/I neurotransmission and the behavior of the animals.

\section{Materials and Methods}

\section{Animals and Experimental Treatment}

Two different transgenic mice strains, purchased from The Jackson Laboratory were used in our experiments: the GIN mice [EGFP-expressing inhibitory neurons, Tg(GadGFP)45704Swn], which express the enhanced green fluorescent protein (EGFP) in a subpopulation of interneurons of interest (Oliva et al. 2000); and the THY1 mice (Thy1-YFP line $\mathrm{H}$ ), which express the yellow fluorescent protein (YFP) in a subset of pyramidal neurons (Feng et al. 2000). The experimental procedure was performed twice for the GIN mice and once for the THY1 mice (Fig. 

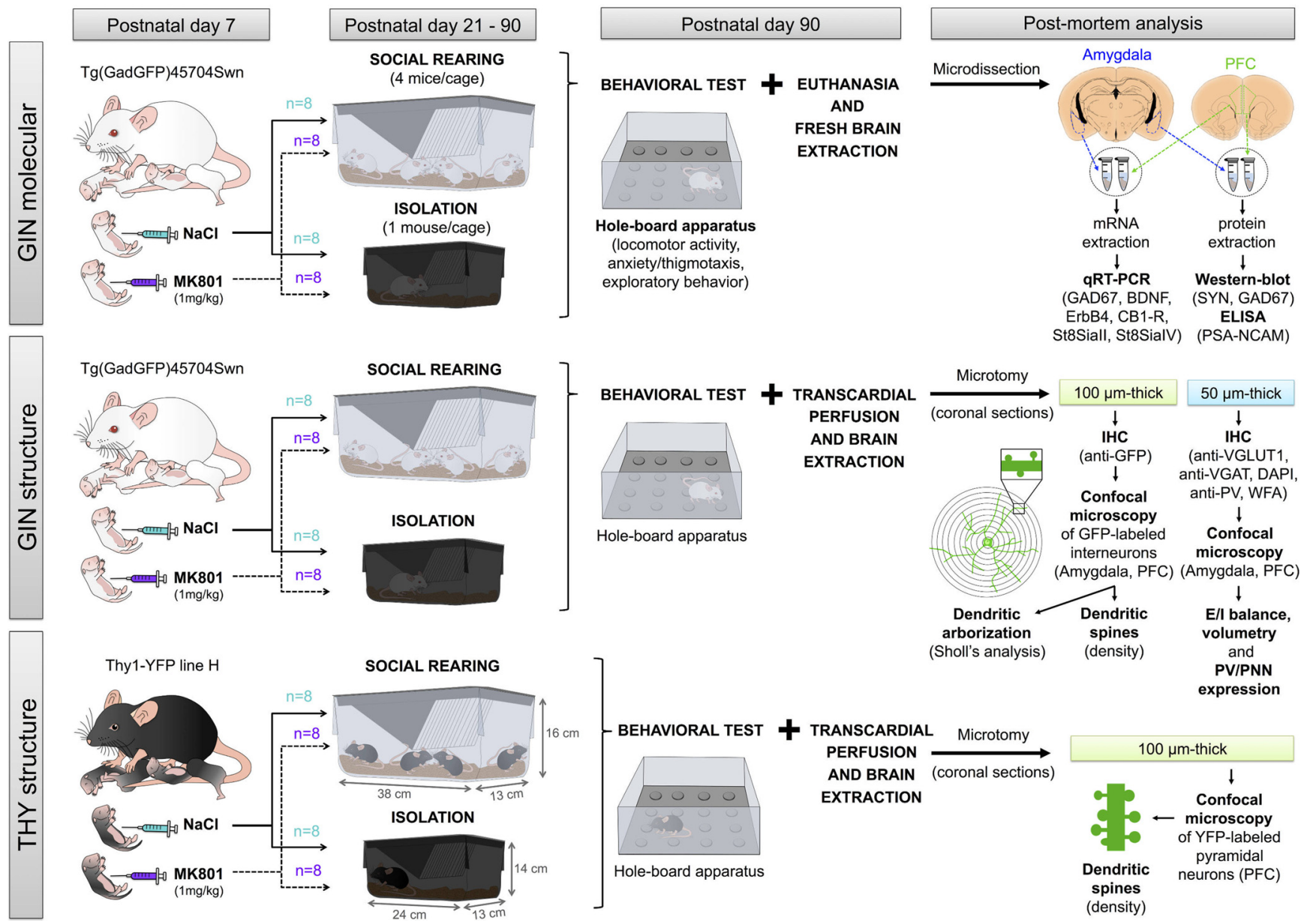

Figure 1. Experimental procedure. Seven days after birth (P7), male pups from two different transgenic strains: the GIN mice (Oliva et al. 2000), which express EGFP in interneurons, and the THY1 mice (Feng et al. 2000), which express the YFP in pyramidal neurons) were intraperitoneally injected with $\mathrm{MK} 801$ or $\mathrm{NaCl}$ (vehicle solution). After weaning (P21), mice were randomly selected and housed alone (isolation) or in groups of four mice (social rearing) for 10 weeks. At P90, all mice were tested in the hole-board apparatus. Brains from GIN molecular mice were destined to protein and gene expression studies, whereas brains from GIN structure mice were used for the structural and neurochemical analysis of interneurons. The THY structure set of mice was used to study structural alterations of pyramidal neurons. For further details, see Material and Methods.

1). One set of the GIN mice $(n=32)$ was used for the structural and neurochemical analysis of interneurons ("GIN structure"), and the other set $(n=32)$ was used for molecular analyses ("GIN molecular"). All THY mice ( $n=$ 32) were used for the structural analysis of pyramidal neurons ("THY structure"). The following procedure refers to any of the three sets. Breeding cages containing one male and two female mice ( 3 months old) were maintained in our animal facility under standard conditions of temperature and light (12 h light/dark cycle) and ad libitum access to food and water. Once the females were pregnant, they were housed individually to avoid any disturbances among mice. Seven days after birth (P7), male pups received randomly a single intraperitoneal injection of MK801 (1 mg/kg solved in $\mathrm{NaCl} 0.9 \%$, Abcam) or the vehicle solution ( $\mathrm{NaCl} 0.9 \%)$. This dose and age of administration produced alterations in PFC-dependent behavior and changes in the structure and inhibitory networks of this region (Lyall et al. 2009; Gilabert-Juan et al. 2013a). MK801, also known as dizocilpine, is a noncompetitive antagonist of
NMDA receptors. After the injection, pups were returned to their cages and remained with their mother until the age of weaning (P21). At this age, eight mice from each of the former groups ( $\mathrm{NaCl}$ or MK801) were randomly selected and housed alone (social isolation) in small polycarbonate cages $(24 \times 14 \times 13 \mathrm{~cm}$; Zoonlab-Bioscapey) or in groups of three to four mice (social housing) in standard-size cages $(38 \times$ $16 \times 13 \mathrm{~cm}$; Zoonlab-Bioscape) for 10 weeks (P90). Thus, at this point, the four final experimental groups $(n=8$ mice/ group) were determined: $\mathrm{NaCl}-\mathrm{Social}$ (injected with vehicle at $\mathrm{P} 7$, and socially housed after weaning), $\mathrm{NaCl}$-Isolation (injected with vehicle but isolated after weaning), MK801Social (injected with MK-801 at P7 and reared in group), and MK801-Isolation or double-hit model (injected with MK801 at P7 and isolated after weaning). All mice were housed in the same room, sharing the same controlled-environment. Isolated mice were able to hear and smell other mice but physical or visual contact with them was not allowed (Fig. 1).

All animal experimentation was conducted in accordance with the Directive 2010/63/EU of the European 
Parliament and of the Council of 22 September 2010 on the protection of animals used for scientific purposes and was approved by the Committee on Bioethics of the Universitat de València. Every effort was made to minimize the number of animals used and their suffering.

\section{Behavioral Analyses}

Before their sacrifice (P90), all mice were tested in the hole-board apparatus (ANY-maze video tracking system v4.98; Stoelting Europe). The hole-board test measures directed exploration but can also be used as an initial basic screen for working memory (Karl et al. 2008), locomotor activity, and anxiety-related behavior (CastillaOrtega et al. 2010; Torres-García et al. 2012; Fig. 1). The open-field chamber $(40 \times 40 \mathrm{~cm})$ was fitted with a holeboard floor insert for mice $(16$ holes, diameter $=2.8 \mathrm{~cm}$, non-baited). Testing of male mice took place between 1 and $2 \mathrm{~h}$ after the onset of the dark phase (illumination at floor level $<2 \mathrm{~lx}$ ). Each mouse was placed in the center of the arena and was left to explore the environment for 7 min (test session). The video tracking system and the infrared photobeams provided automated measures of the following: (1) total distance traveled and mean speed (to study locomotor activity); (2) head dips, for the study of exploratory behavior (number of head dips into novel holes/total number of head dips; Karl et al. 2008); and (3) body rotations $\left(360^{\circ}\right)$ and number of entries and time spent in the periphery of the arena, for the measure of anxiety and thigmotaxis (a valid index of anxiety in mice; Simon et al. 1994). The periphery zone of the area was defined as the area located between 0 and $6 \mathrm{~cm}$ away the walls of the apparatus (Figs. 1,2A,3A).

\section{Perfusion, Microtomy, and Immunohistochemistry}

At P90, GIN structure and THY structure mice were deeply anesthetized with sodium pentobarbital and transcardially perfused with $4 \%$ paraformaldehyde solution for 20 min. Thirty minutes after perfusion, brains were extracted from the skull and their hemispheres were separated. One hemisphere was cryoprotected [ $30 \%$ sucrose in phosphate buffer (PB) $0.1 \mathrm{M}, 48 \mathrm{~h}$ ] and afterward cut in $50-\mu \mathrm{m}$-thick coronal sections using a freezing-sliding microtome (LEICA SM2000R, Leica) for immunohistochemical analysis. The other hemisphere, destined to the study of the neuronal structure, was cut in 100- $\mu \mathrm{m}$-thick coronal sections with a vibratome (Leica VT 1000E, Leica; Fig. 1).

After cutting, tissue was counterstained with DAPI (50$\mu \mathrm{m}$-thick sections for volumetric studies; see below) or processed free-floating for fluorescence immunohistochemistry as follows (Fig. 1). Briefly, sections were washed in PBS and then incubated for $1 \mathrm{~h}$ in $10 \%$ normal donkey serum (NDS; Abcys) in PBS with $0.2 \%$ Triton X-100 (PBST; Sigma-Aldrich). Afterward, they were incubated for $48 \mathrm{~h}$ at $4^{\circ} \mathrm{C}$ with the appropriate primary antibody or antibody cocktail diluted in PBST and 5\% NDS: (a) polyclonal chicken IgY anti-GFP (1:1000, Abcam) in 100- $\mu \mathrm{m}$ thick sections from GIN mice to enhance EGFP signal for the structural study of interneurons; (b) polyclonal guinea pig anti-vesicular glutamate transporter 1 (VGLUT1; 1:2000, Merck-Millipore) and monoclonal IgG mouse anti-vesicular GABA transporter (VGAT; 1:1000, Synaptic Systems) in $50-\mu \mathrm{m}$-thick sections to study excitatory and inhibitory neurotransmission in the neuropil; (c) polyclonal rabbit IgG anti-PV (1:2000, Swant) and biotin-conjugated Wisteria floribunda agglutinin (1:200, Sigma-Aldrich) in 50- $\mu \mathrm{m}-$ thick sections to study the coexpression of PV and PNNs in the amygdala and PFC. After washing, sections were incubated for $2 \mathrm{~h}$ at room temperature with matching secondary antibodies (1:400, Jackson ImmunoResearch) diluted in PBST and 5\% NDS: (a) donkey anti-chicken DyLight-488-conjugated, (b) goat anti-guinea Pig DyLight649-conjugated and goat anti-mouse IgG AlexaFluor-555conjugated, and (c) donkey anti-rabbit IgG AlexaFluor-555conjugated and Avidin AlexaFluor-647-conjugated. Finally, sections were washed in PB $0.1 \mathrm{M}$, mounted on slides, and coverslipped using fluorescence mounting medium (Dako Diagnósticos).

\section{Volumetry}

A volumetric analysis of the different nuclei of the amygdala (central, lateral, medial, basolateral, and basomedial) and regions of the PFC (infralimbic, prelimbic, dorsal cingulate, and ventral cingulate cortices) were performed by processing confocal images using the Volumest plugin of FlJI/ImageJ Software $(\mathrm{NIH}$; Schindelin et al. 2012). To be able to differentiate the different regions of interest in the subsets of slices, $50-\mu \mathrm{m}$-thick sections from the GIN structure set of mice $(n=32)$ were counterstained with DAPI $\left(1: 10,000\right.$ in $\mathrm{H}_{2} \mathrm{O}$, SigmaAldrich). Images of the regions-of-interest were acquired using a confocal microscope (Olympus FV-10). Volumes were estimated using Cavalieri's principle (Gundersen and Jensen, 1987).

\section{Analysis of Dendritic Arborization and Dendritic Spine Density}

All the structural parameters of the GAD-EGFP interneurons and THY1-YFP pyramidal neurons were studied using a laser scanning confocal microscope (Leica TCS SPE). In the case of pyramidal neurons, we focused our studies on the PFC, in particular, on the cingulated cortices because, due to the straight projection of the principal dendrite of pyramidal neurons to layer 1 , it is only visible coronally in these two subregions of the PFC. To be consistent, interneurons were studied in the same subregions of the PFC. In addition, we studied the arborization and dendritic spine density of interneurons in the basolateral nucleus of the amygdala, which is known to project directly to the PFC and has an abundant population of fluorescent interneurons in GIN mice. Unfortunately, due to the overwhelming expression of the YFP in the amygdala, we could not to perform these structural analyses for pyramidal neurons.

For the study of the dendritic arborization, six GAD-GFP expressing interneurons per animal and region were randomly selected (Fig. 1). Z-series of optical sections (0.8 $\mu \mathrm{m}$ step size; $40 \times$ objective) covering the dendritic tree of selected interneurons were obtained using the sequential scanning mode. To be suitable for analysis, these interneurons had to fulfill the following features: (1) the cell must not show any truncated dendrites, (2) the dendritic arbor of the cell must show at least a process with a 
A

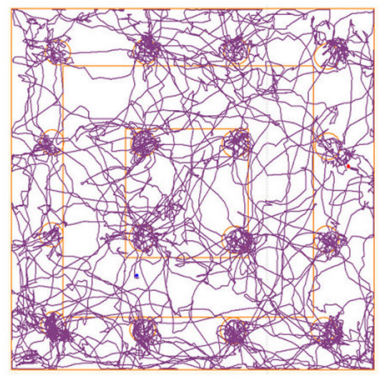

$\mathrm{NaCl}-\mathrm{Social}$

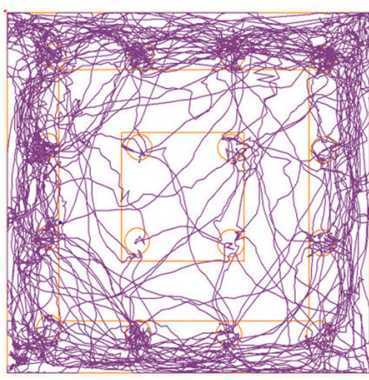

$\mathrm{NaCl}$-Isolation

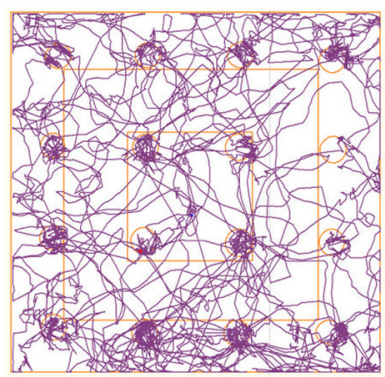

MK801-Social

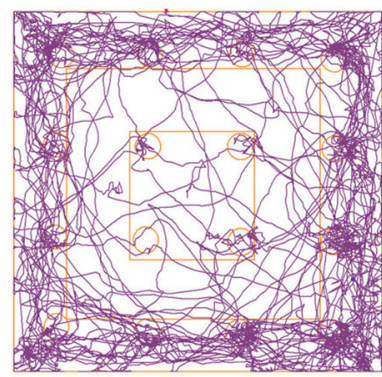

MK801-Isolation
B

\section{Locomotor activity}

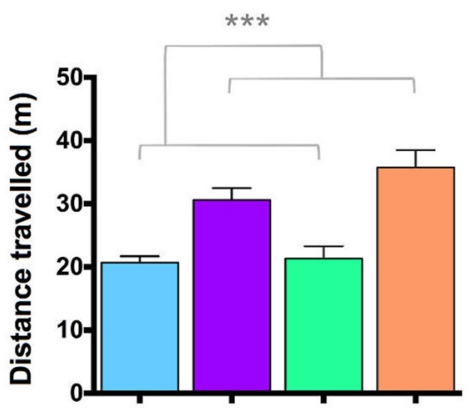

D

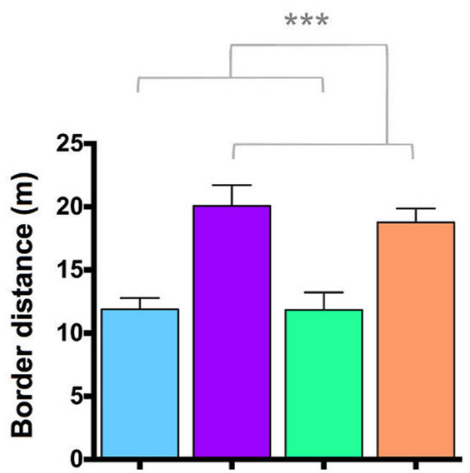

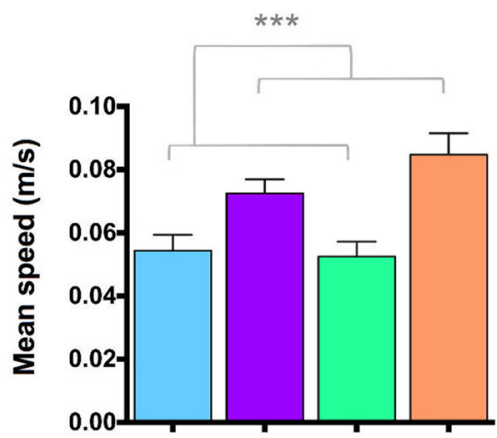

\section{Exploratory behavior}

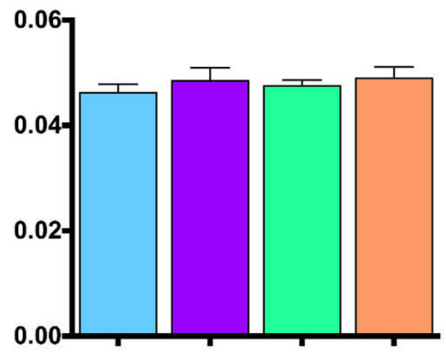

\section{Anxiety-related behavior}
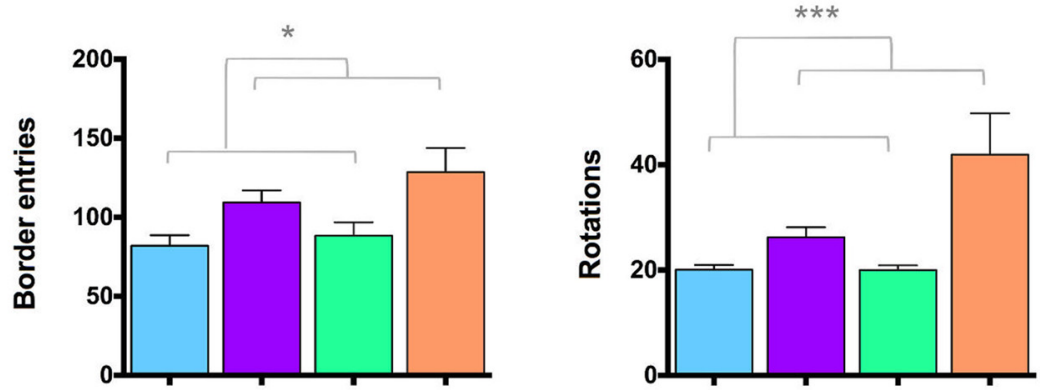

MK801-Social

$\mathrm{NaCl}-$ Isolation

Figure 2. Behavioral analysis of GAD-EGFP expressing mice. $\boldsymbol{A}$, Representative track-plot reports recorded during the hole-board test session (ANY-maze). Observe the increased distance traveled (purple line) in the two groups subjected to post-weaning isolation, especially in the border of the apparatus. Social isolation rearing increased locomotor activity $(\boldsymbol{B})$ and anxiety-related behavior $(\boldsymbol{D})$ but did not change exploratory behavior (number of head dips into novel holes/total number of head dips; $\boldsymbol{C})$. Gray lines in graphs $(\boldsymbol{B}-\boldsymbol{D})$ represent statistically significant effects of rearing in a two-way ANOVA. $* p<0.05, * * p<$ $0.01, * * * p<0.001$ 
A

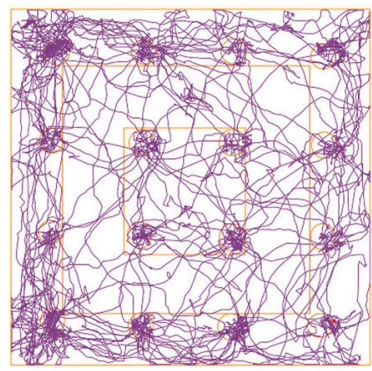

$\mathrm{NaCl}-S o c i a l$

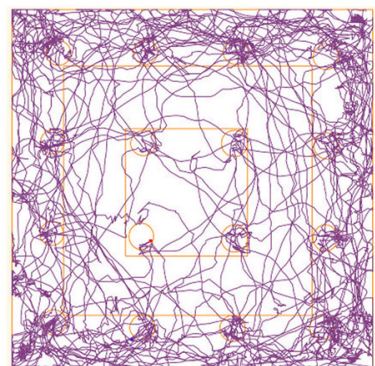

$\mathrm{NaCl}$-Isolation

Thy1-YFP mice

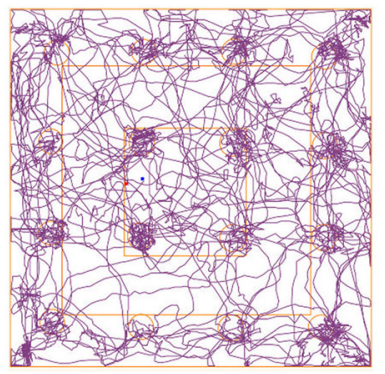

MK801-Social

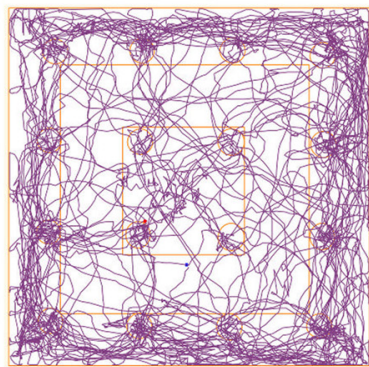

MK801-Isolation
B

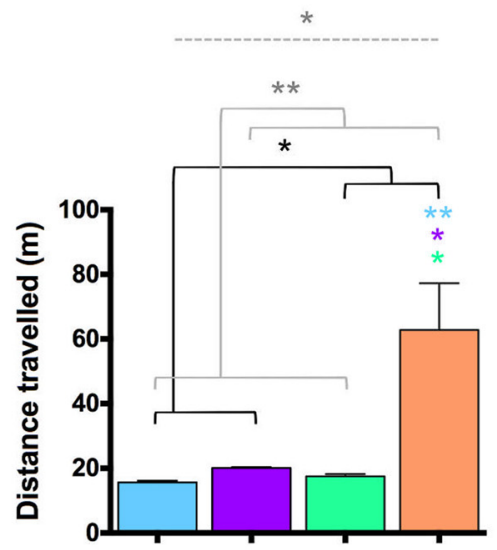

D

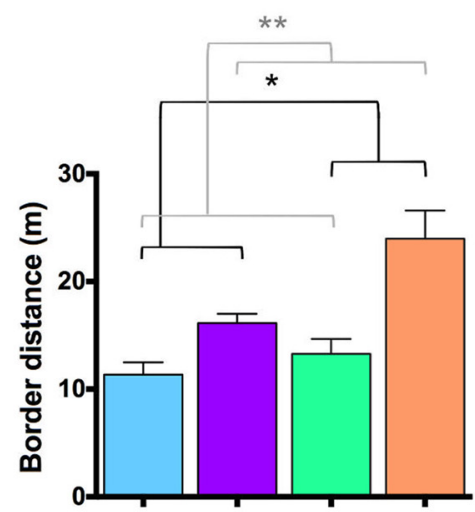

\section{Exploratory} behavior

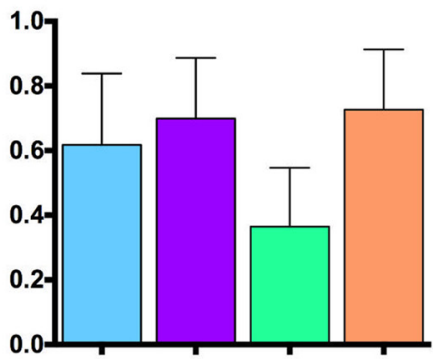

\section{Anxiety-related behavior}
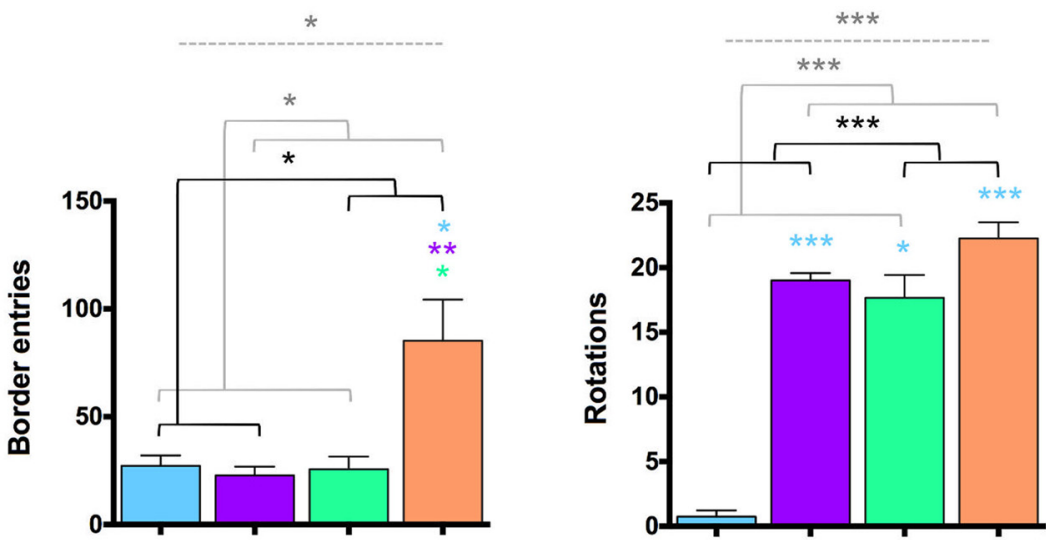

$\mathrm{NaCl}$-Social

$\mathrm{NaCl}-$ Isolation

MK801-Social

MK801-Isolation

Figure 3. Behavioral analysis of Thy1-YFP expressing mice. $\boldsymbol{A}$, Representative track-plot reports showing the increased distance traveled (purple line) of double-hit mice (MK801-Isolation group) in the hole-board test compared with the other groups. Double-hit mice showed increased locomotor activity $(\boldsymbol{B})$ and anxiety-related behavior $(\boldsymbol{D})$ but no changes in exploratory behavior (number of head dips into novel holes/total number of head dips; $\boldsymbol{C}$ ). $\boldsymbol{B}-\boldsymbol{D}$, Horizontal lines in graphs represent statistically significant effects of MK801 treatment (black), rearing (gray), or interaction (gray, dashed) in a two-way ANOVA. $* p<0.05, * * p<0.01, * * * p<0.001$. Colored symbols in bars represent trends and statistically significant differences among groups after post hoc analysis: $\# 0.1>p>0.05, * p<0.05, * * p<0.01, * * * p<0.001$. 
length $>150 \mu \mathrm{m}$, and (3) the soma must be located at least $30 \mu \mathrm{m}$ deep from the surface of the tissue. The stacks obtained were then processed using FIJI (ImageJ, $\mathrm{NIH}$ ) software to render 3D reconstructions. Neurons were traced using the "Simple neurite tracer" plugin, which also allowed us to analyze their Sholl profile in 3D (Longair et al. 2011; Fig. 1). The Sholl analysis consists on the measure of the number of intersections of the dendrites with spheres of increasing radius centered in the soma. The separation among the spheres of the analysis was set at $20 \mu \mathrm{m}$. For each animal, mean \pm SEM was calculated and statistics were performed using the number of animals and the sample number ( $n$; see below).

For the analysis of dendritic spines, six GAD-GFP expressing interneurons and six THY1-YFP expressing pyramidal neurons per animal and region were randomly selected (Fig. 1). A $63 \times$ oil immersion objective and a $3.5 \times$ additional digital zoom were used to observe the first $150 \mu \mathrm{m}$ of the dendrite in the case of interneurons and the first $200 \mu \mathrm{m}$ of the dendrite in the case of pyramidal neurons in segments of $50 \mu \mathrm{m}$ (Z-step size of 0.38 $\mu \mathrm{m})$. Dendrites within EGFP- and YFP-positive interneurons were randomly selected, but they had to meet the following criteria to be included in the study: (1) their length should be at least $150 \mu \mathrm{m}$ (for interneurons) or 200 $\mu \mathrm{m}$ (for pyramidal neurons), and (2) no other dendrites should be found crossing their trajectory. For interneurons, data were expressed as the total number of spines in the proximal $(0-50 \mu \mathrm{m})$, medial $(50-100 \mu \mathrm{m})$, and distal $(100-150 \mu \mathrm{m})$ segments of the dendrite, depending on its distance from the soma. For pyramidal neurons, four segments were established: proximal $(0-50 \mu \mathrm{m})$, medial $(50-100 \mu \mathrm{m})$, medial-distal $(100-150 \mu \mathrm{m})$, and distal $(150-200 \mu \mathrm{m})$. The total number of spines in every dendrite (sum of the spines in the entire segment) was also analyzed. For each animal, mean \pm SEM was calculated and statistics were performed using the number of animals and the sample number ( $n$; see below).

\section{Analysis of VGLUT1 and VGAT Puncta Density in the Neuropil and Calculation of the E/I Ratio}

The images used for the analysis of neuropil puncta expressing inhibitory (VGAT) or excitatory (VGLUT1) markers were obtained with a confocal microscope (Olympus FV-10). We analyzed layer 5 of the different regions of the PFC (infralimbic, prelimbic, dorsal cingulate, and ventral cingulate cortices). In the amygdala, the five nuclei were analyzed (central, lateral, medial, basolateral, and basomedial). Confocal z-stacks covering the whole depth of the sections were taken with $1 \mu \mathrm{m}$ step size and only subsets of confocal planes with the optimal penetration level for each antibody were selected. On these planes, small regions of the neuropil $\left(505 \mu \mathrm{m}^{2}\right)$ were selected for analysis to avoid blood vessels and cell somata. Images were processed using FIJI/ImageJ software as described (Guirado et al. 2012): the background was subtracted with rolling value of 50 , converted to 8 -bit deep images and binarized using a determined threshold value. This value depended on the marker and the area analyzed and was kept the same for all images with the same marker and area. Then, the images were processed with a blur filter to reduce noise and to separate closely apposed puncta. Finally, the number of the resulting dots per region was counted. The E/I ratio was calculated as the density of VGLUT1 expressing puncta divided by the density of inhibitory VGAT expressing puncta. For each animal, mean \pm SEM was calculated and statistics were performed using the number of animals and the sample number ( $n$; see below).

\section{Estimation of the Total Number of PV-Expressing Neurons, PNN, and PV-PNN Colocalization}

The total number of $\mathrm{PV}$-expressing $(\mathrm{PV}+)$ neurons, PNNs, and PV + neurons surrounded by PNNs from the different nuclei/regions of the amygdala and PFC were estimated using a modified version of the fractionator method (West, 1993; Nacher et al. 2002). That is, within each $50-\mu \mathrm{m}$-thick section of one from the six systematicrandom series of sections, all labeled cells covering the $100 \%$ of the sample area were counted. The images used for the analysis were obtained with a confocal microscope (Olympus FV-10) and processed afterward using FIJI/ ImageJ software. For each animal, mean \pm SEM was calculated and statistics were performed using the number of animals as the sample number ( $n$; see below).

\section{Sample Preparation for Molecular Studies}

A total of 32 mice encompassing the four experimental groups (GIN molecular set of mice) were used for protein and gene expression analyses. Mice were sacrificed by decapitation at P90 under deep anesthesia with sodium pentobarbital. Their brains were quickly removed from the skull and the amygdala and PFC from both hemispheres were microdissected and immediately frozen in liquid nitrogen. The samples from one of the hemispheres of every animal were processed for protein extraction and the samples from the other hemisphere for mRNA extraction (Fig. 1).

For protein extraction, tissue was homogenized in $50 \mu \mathrm{l}$ of lysis buffer using a TissueLyser (Qiagen) and Tungsten carbide beads for 5 min at $50 \mathrm{~Hz} / \mathrm{s}$ and $4^{\circ} \mathrm{C}$. Lysis buffer was made solving one pill of protease inhibitor cocktail (Ref. 04693124001, Roche Applied Science) in $1 \mathrm{ml}$ of PBS-1\% Triton X-100. Samples were afterward centrifuged at $16000 \times g$ and $4^{\circ} \mathrm{C}$ for 4 min and supernatant was assessed for the total amount of protein using Bradford reagent at $595 \mathrm{~nm}$ with bovine serum albumin as the standard (Sigma-Aldrich).

Total mRNA was extracted from the tissue using TriPure reagent (Roche Applied Science) and following the manufacturer's instructions. The concentration and purity of total RNA was determined with an Eppendorf BioPhotometer Plus (Eppendorf AG). cDNA synthesis was performed using the Expand Reverse Transcriptase (Roche Applied Science) and oligo-dT primers.

\section{Protein Expression}

Quantitative immunoblotting of synaptophysin and GAD67

Twenty micrograms of total protein from each sample was separated on $10 \%$ SDS-PAGE and transferred to Hybond enhanced chemiluminescence (ECL) nitrocellu- 
Table 1. Sequences of gene specific primers and associated amplicon lengths for qRT-PCR

\begin{tabular}{|c|c|c|c|}
\hline Target gene & Primers & Sequence $\left(5^{\prime} \rightarrow 3^{\prime}\right)$ & Amplicon size* \\
\hline GAD67 & $\begin{array}{l}\text { Forward } \\
\text { Reverse }\end{array}$ & $\begin{array}{l}\text { CTGGAGCTGGCTGAATACCT } \\
\text { TCGGAGGCTTTGTGGTATGT }\end{array}$ & 120 \\
\hline$B D N F$ & $\begin{array}{l}\text { Forward } \\
\text { Reverse }\end{array}$ & $\begin{array}{l}\text { GGTTCGAGAGGTCTGACGAC } \\
\text { CAAAGGCACTTGACTGCTGA }\end{array}$ & 159 \\
\hline ErbB4 & $\begin{array}{l}\text { Forward } \\
\text { Reverse }\end{array}$ & $\begin{array}{l}\text { CAGTCGCCCAGGGTGCAACG } \\
\text { GCGAACACTGTGGGGTCGGC }\end{array}$ & 133 \\
\hline$C B 1-R$ & $\begin{array}{l}\text { Forward } \\
\text { Reverse }\end{array}$ & $\begin{array}{l}\text { TGTCCCTCACCCTGGGCACC } \\
\text { TCCCAGGAGATCGGCCACCG }\end{array}$ & 134 \\
\hline ST8Siall & $\begin{array}{l}\text { Forward } \\
\text { Reverse }\end{array}$ & $\begin{array}{l}\text { GGCAACTCAGGAGTCTTGCT } \\
\text { GTCAGTCTTGAGGCCCACAT }\end{array}$ & 123 \\
\hline ST8SiaIV & $\begin{array}{l}\text { Forward } \\
\text { Reverse }\end{array}$ & $\begin{array}{l}\text { CCTTCATGGTCAAAGGAGGA } \\
\text { CСTTCATGGTCAAAGGAGGA }\end{array}$ & 125 \\
\hline Ywhaz & $\begin{array}{l}\text { Forward } \\
\text { Reverse }\end{array}$ & $\begin{array}{l}\text { TTGAGCAGAAGACGGAAGGT } \\
\text { GAAGCATTGGGGATCAAGAA }\end{array}$ & 136 \\
\hline
\end{tabular}

${ }^{*}$ Amplicon length in base pairs.

lose membranes (GE Healthcare). After saturation of nonspecific sites with blocking buffer (5\% nonfat dry milk in PBS-0.025\%Tween 20 , overnight, $4^{\circ} \mathrm{C}$ ), membranes were probed for $2 \mathrm{~h}$ at room temperature with primary antibodies against synaptophysin (1:5000, Sigma-Aldrich), GAD67 (1: 1000, Merck-Millipore) or the control protein $\alpha$-tubulin (1: 5000 , Sigma-Aldrich), all of them diluted in blocking buffer. After washing with PBS-0.025\%Tween 20, membranes were incubated for $2 \mathrm{~h}$ with the appropriate secondary horseradish peroxidase-linked antibodies (1:2500, SigmaAldrich), and finally developed using ECL detection reagents (Thermo Scientific). Bands were detected using ImageQuant LAS4000 system (GE Health care) and densitometry analysis on every band was calculated using FIJl/ImageJ software (NIH). Synaptophysin and GAD67 densitometry values were normalized to within-lane $\alpha$-tubulin. Every sample was immunoblotted in duplicate and mean \pm SEM was then calculated. Statistics were performed using the number of animals as the sample number $(n)$.

\section{ELISA for PSA-NCAM assessment}

PSA-NCAM protein levels were quantified in the same samples that were used for synaptophysin and GAD67 quantification, by performing commercially available ELISA kits (Eurobio/AbCys). A total volume of $100 \mu \mathrm{l}$ of each sample was loaded at a concentration of $4 \mu \mathrm{g} / \mathrm{ml}$ per well in duplicates. PSA-NCAM levels (ng PSA $\mu \mathrm{g}$ of total protein) were calculated according to the manufacturer's protocol. Statistics were performed using the number of animals and the sample number $(n)$.

\section{Gene Expression}

qRT-PCR analyses were performed in triplicate. Specific primers for all genes (Table 1) at a concentration of $240 \mathrm{~nm}$, and $4 \mu \mathrm{l}$ of cDNA (50 ng) were used. Primers were designed between exons to avoid genomic DNA contamination when possible. Ywhaz was used as a reference gene based on the study of Bonefeld et al. (2008). Primers were tested for nonspecific amplification and for the correct amplicon size by electrophoresis in $1.5 \%$ agarose gel. qPCR was conducted with the ABI PRISM 7700 Sequence Detector (Applied Biosystems) using SYBR Green PCR master mix (Applied Biosystems), following a $95^{\circ} \mathrm{C}$ denaturation for $10 \mathrm{~min}$. The reactions were cycled 40 times with a $95^{\circ} \mathrm{C}$ denaturation for $15 \mathrm{~s}$, and a $60^{\circ} \mathrm{C}$ annealing step for $1 \mathrm{~min}$. After this, a melt curve was performed to assess the specificity of primers.

Relative quantification was performed using the comparative threshold $\left(C_{t}\right)$ method according to the $2^{-\Delta \Delta C t}$ method (Pfaffl, 2001). Changes in gene expression were reported as fold-change relative to controls and the statistics were performed as described below.

\section{Statistics}

Group differences in all our studies were assessed using two-way ANOVA with the number of animals as the sample number ( $n$ ). When interaction between treatment (MK801 vs vehicle) and rearing (social vs isolation) was statistically significant $(p<0.05)$, multiple pairwise comparisons between groups (Tukey HSD or Games-Howell post hoc analyses) were performed. Analysis were performed using the statistical package SPSS v22.0 (IBM) and graphs were created using GraphPad Prism 6. Data in the figures are expressed as mean \pm SEM and $p<0.05$ are indicated.

\section{Results}

Increased Locomotion and Anxiety-Related Behavior

Early-life stress induced hyperlocomotion and increased anxiety-related behavior in GIN mice, whereas exploratory behavior was not affected (Fig. 2; Table 2). Specifically, double-hit animals (MK801-Isolation) and isolated animals showed increased distance traveled, speed, number of body rotations, and thigmotaxis (increased distance traveled in the periphery zone of the apparatus and increased number of entries to this zone; Fig. $2 B-D$ ). Similar results were found when analyzing the behavior of THY1 mice, but in this case, specific significant increases were found in most of the parameters measured for locomotor activity (Fig. $3 A, B$ ) and anxietyrelated behavior (Fig. 3D) when comparing double-hit to control mice. Exploratory behavior was also not affected in this strain (Fig. 3C). Detailed information on statistical tests can be found in Table 2 . 
Table 2. Summary of results (part I)

\begin{tabular}{|c|c|c|c|c|c|c|}
\hline \multirow{3}{*}{$\begin{array}{l}\text { Parameter } \\
\text { Behavior (Figs. 2, 3) }\end{array}$} & \multicolumn{3}{|c|}{ Main effects (two-way ANOVA) } & \multicolumn{3}{|c|}{ Group differences (from NaCl-Social) } \\
\hline & Treatment & Rearing & Interaction & $\mathrm{NaCl}$-Isolation & MK801-Social & MK801-Isolation \\
\hline & & & & & & \\
\hline \multicolumn{7}{|l|}{$\begin{array}{l}\text { Behavior (FIgs. } 2,3 \text { ) } \\
\text { Locomotor activity }\end{array}$} \\
\hline \multicolumn{7}{|c|}{ Total distance travelled } \\
\hline Gad-EGFP mice & - & $\mathfrak{S}^{(1)}$ & - & $\mathrm{n} / \mathrm{a}$ & $\mathrm{n} / \mathrm{a}$ & $\mathrm{n} / \mathrm{a}$ \\
\hline Thy1-YFP mice & $\mathfrak{S}^{(2)}$ & $\mathfrak{S}^{(3)}$ & $\mathfrak{S}^{(4)}$ & - & - & $\uparrow^{* * *}$ \\
\hline \multicolumn{7}{|l|}{ Mean speed } \\
\hline Gad-EGFP mice & - & $\mathfrak{S}^{(5)}$ & - & $\mathrm{n} / \mathrm{a}$ & $\mathrm{n} / \mathrm{a}$ & $\mathrm{n} / \mathrm{a}$ \\
\hline Thy1-YFP mice & $\mathcal{S}^{(6)}$ & $\mathfrak{S}^{(7)}$ & $\mathfrak{S}^{(8)}$ & - & - & $\uparrow * *$ \\
\hline \multicolumn{7}{|c|}{ Anxiety-related behavior } \\
\hline \multicolumn{7}{|c|}{ Border distance } \\
\hline Gad-EGFP mice & - & $\sqrt{ }^{(9)}$ & - & $\mathrm{n} / \mathrm{a}$ & $\mathrm{n} / \mathrm{a}$ & $\mathrm{n} / \mathrm{a}$ \\
\hline Thy1-YFP mice & $\mathfrak{S}^{(10)}$ & $\mathfrak{S}^{(11)}$ & - & $\mathrm{n} / \mathrm{a}$ & $\mathrm{n} / \mathrm{a}$ & $\mathrm{n} / \mathrm{a}$ \\
\hline \multicolumn{7}{|l|}{ Border entries } \\
\hline Gad-EGFP mice & - & $\mathfrak{J}^{(12)}$ & - & $\mathrm{n} / \mathrm{a}$ & $\mathrm{n} / \mathrm{a}$ & $\mathrm{n} / \mathrm{a}$ \\
\hline Thy1-YFP mice & $\mathfrak{J}^{(13)}$ & $\mathfrak{J}^{(14)}$ & $\mathfrak{J}^{(15)}$ & - & - & $\uparrow^{*}$ \\
\hline \multicolumn{7}{|l|}{ Body rotations } \\
\hline Gad-EGFP mice & - & $\mathfrak{J}^{(16)}$ & - & $\mathrm{n} / \mathrm{a}$ & $\mathrm{n} / \mathrm{a}$ & $\mathrm{n} / \mathrm{a}$ \\
\hline Thy1-YFP mice & $\mathfrak{S}^{(17)}$ & $\mathfrak{S}^{(18)}$ & $\mathscr{S}^{(19)}$ & $\uparrow^{* * * *}$ & $\uparrow^{*}$ & $\uparrow^{* * * *}$ \\
\hline \multicolumn{7}{|l|}{ Exploratory behavior } \\
\hline Gad-EGFP mice & - & - & - & $\mathrm{n} / \mathrm{a}$ & $\mathrm{n} / \mathrm{a}$ & $\mathrm{n} / \mathrm{a}$ \\
\hline Thy1-YFP mice & - & - & - & $\mathrm{n} / \mathrm{a}$ & $\mathrm{n} / \mathrm{a}$ & $\mathrm{n} / \mathrm{a}$ \\
\hline \multicolumn{7}{|l|}{ Brain volume (Fig. 4) } \\
\hline \multicolumn{7}{|l|}{ Amygdala } \\
\hline Total volume & - & - & $\#^{(20)}$ & $\mathrm{n} / \mathrm{a}$ & $\mathrm{n} / \mathrm{a}$ & $\mathrm{n} / \mathrm{a}$ \\
\hline Central & - & - & $\mathscr{J}^{(21)}$ & $\uparrow^{*}$ & - & - \\
\hline Lateral & - & - & - & $\mathrm{n} / \mathrm{a}$ & $\mathrm{n} / \mathrm{a}$ & $\mathrm{n} / \mathrm{a}$ \\
\hline Basolateral & 一 & $\mathfrak{J}^{(22)}$ & - & $\mathrm{n} / \mathrm{a}$ & $\mathrm{n} / \mathrm{a}$ & $\mathrm{n} / \mathrm{a}$ \\
\hline Basomedial & $\boldsymbol{J}^{(23)}$ & - & - & $\mathrm{n} / \mathrm{a}$ & $\mathrm{n} / \mathrm{a}$ & $\mathrm{n} / \mathrm{a}$ \\
\hline Medial & - & - & - & $n / a$ & $\mathrm{n} / \mathrm{a}$ & $\mathrm{n} / \mathrm{a}$ \\
\hline \multicolumn{7}{|l|}{ PFC } \\
\hline Total volume & - & $\#^{(24)}$ & - & $\mathrm{n} / \mathrm{a}$ & $\mathrm{n} / \mathrm{a}$ & $\mathrm{n} / \mathrm{a}$ \\
\hline IL & - & $\#^{(25)}$ & - & $\mathrm{n} / \mathrm{a}$ & $\mathrm{n} / \mathrm{a}$ & $\mathrm{n} / \mathrm{a}$ \\
\hline PrL & - & - & - & $\mathrm{n} / \mathrm{a}$ & $\mathrm{n} / \mathrm{a}$ & $\mathrm{n} / \mathrm{a}$ \\
\hline $\mathrm{Cg} 1$ & $\mathfrak{S}^{(26)}$ & - & $\mathcal{S}^{(27)}$ & - & - & $\downarrow \#$ \\
\hline $\mathrm{Cg} 2$ & - & - & - & $\mathrm{n} / \mathrm{a}$ & $\mathrm{n} / \mathrm{a}$ & $\mathrm{n} / \mathrm{a}$ \\
\hline
\end{tabular}

Symbols: $(\checkmark)$ statistically significant effect (two-way ANOVA); $(-)$ no statistically significant effect (two-way ANOVA) or difference from NaCl-Social group (post hoc); ( $\uparrow$ ) increase; (n/a) not applicable; $(\downarrow)$ decrease; $* p<0.05 ; * * p<0.01 ; * * * p<0.001 ; \# 0.10 \geq p \geq 0.05$.

$F$ and $p$ values: (1) $F_{(1,58)}=31.11, p<10^{-6} ;(2) F_{(1,11)}=8.05, p=0.016 ;(3) F_{(1,11)}=9.99, p=0.009 ;(4) F_{(1,11)}=6.74, p=0.025 ;(5) F_{(1.59)}=19.38, p=$ $4.6 \times 10^{-5}$; (6) $F_{(1,11)}=7.80, p=0.018 ;(7) F_{(1,11)}=9.90, p=0.009 ;(8) F_{(1,11)}=6.61, p=0.026 ;(9) F_{(1,59)}=36.48, p<10^{-7} ;(10) F_{(1,11)}=8.22, p=$ 0.015 ; (11) $F_{(1,11)}=20.68, p=0.001 ;(12) F_{(1,60)}=6.20, p=0.016 ;(13) F_{(1,11)}=7.48, p=0.019 ;(14) F_{(1,11)}=6.11, p=0.031 ;(15) F_{(1,11)}=8.27, p=$ $0.015 ;(16) F_{(1,60)}=5.14, p=0.027 ;(17) F_{(1,11)}=93.50, p=10^{-5} ;(18) F_{(1,11)}=119.86, p<10-6 ;(19) F_{(1,11)}=42.94, p=4.1 \times 10^{-5} ;(20) F_{(1,20)}=3.34$, $p=0.082 ;(21) F_{(1,21)}=4.73, p=0.041 ;(22) F_{(1,21)}=9.44, p=0.0058 ;(23) F_{(1,21)}=5.82, p=0.025 ;(24) F_{(1,23)}=3.39, p=0.079 ;(25) F_{(1,23)}=3.61, p=$ $0.07 ;(26) F_{(1,22)}=5.062, p=0.035 ;(27) F_{(1,22)}=6.62, p=0.017$.

\section{Alterations in the Volume of Amygdala and PFC}

We have performed volumetric analyses to test whether the different interventions result in changes in the volumes of the amygdala and the PFC, as some studies have described in schizophrenic patients (Jaaro-Peled et al. 2010; Levitt et al. 2010; Fig. 4). Rearing in social isolation increased the volume of the BLA (Fig. 4B,C) and induced a trend toward an increase in the volume of the infralimbic (IL) cortex (Fig. $4 D, E)$. By contrast, MK-801 treatment decreased the volume of the basomedial amygdala (BMA) (Fig. 4B,C) and the cingulate 1 (Cg1) cortex (Fig. 4D,E). A significant effect of the interaction of both interventions could also be observed in the central (Ce) nuclei of the amygdala (Fig. 4B,C) and the Cg1 cortex (Fig. 4D,E). When performing post hoc analyses, the isolated group of animals showed a significant increase in the volume of the Ce amygdala compared with the control group and double-hit mice showed a significant decrease in the volume of the $\mathrm{Cg} 1$ cortex compared with isolated or MK-801-treated animals (Fig. 4C,E; Table 2).

\section{Structural Alterations of E/I Neurons}

Because these changes in the volume of the different regions studied could be due to changes in the structure of neurons, particularly of dendritic remodeling, we first analyzed spine density in PFC pyramidal neurons. Unfortunately, the characteristics of the strain (Porrero et al. 2010) do not allow for the analysis of dendritic arborization in these PFC neurons or any type of structural analysis in amygdaloid excitatory neurons. Treatment, rearing and their interaction affected the density of spines in different dendritic segments of pyramidal neurons in the PFC (Table 3). There was a decrease in the density of spines in the whole length of the dendrite, in double-hit mice compared with controls, but it was considered 
A

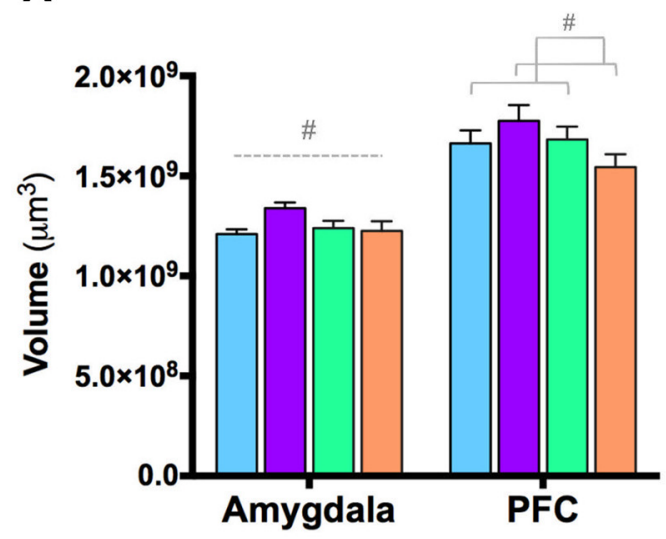

C

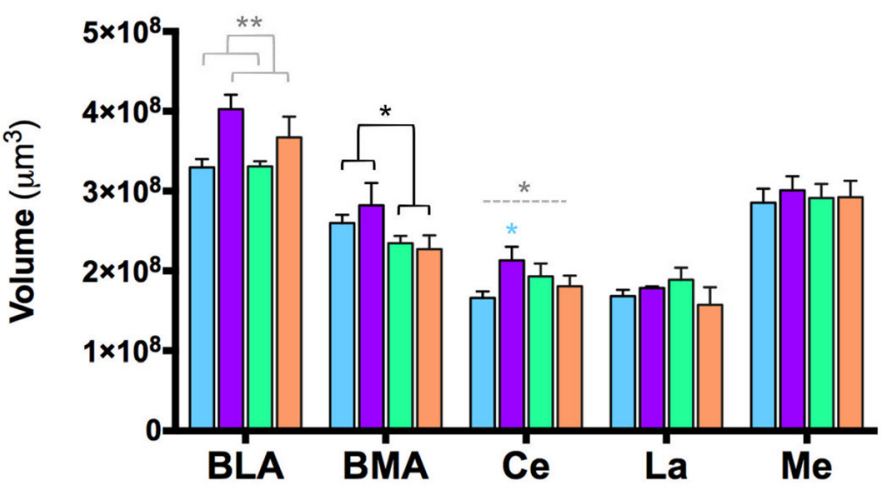

E

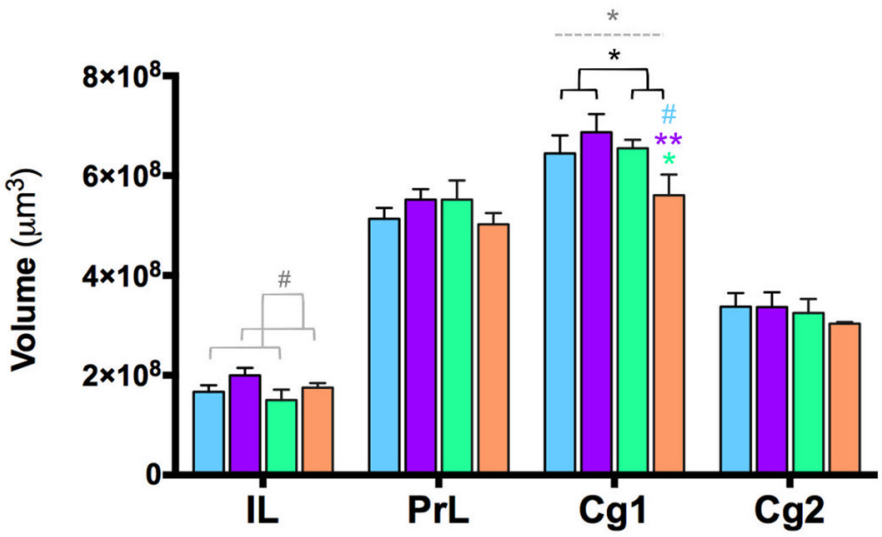

$\mathrm{NaCl}-\mathrm{Social}$

MK801-Social $\mathrm{NaCl}$-Isolation

MK801-Isolation
B

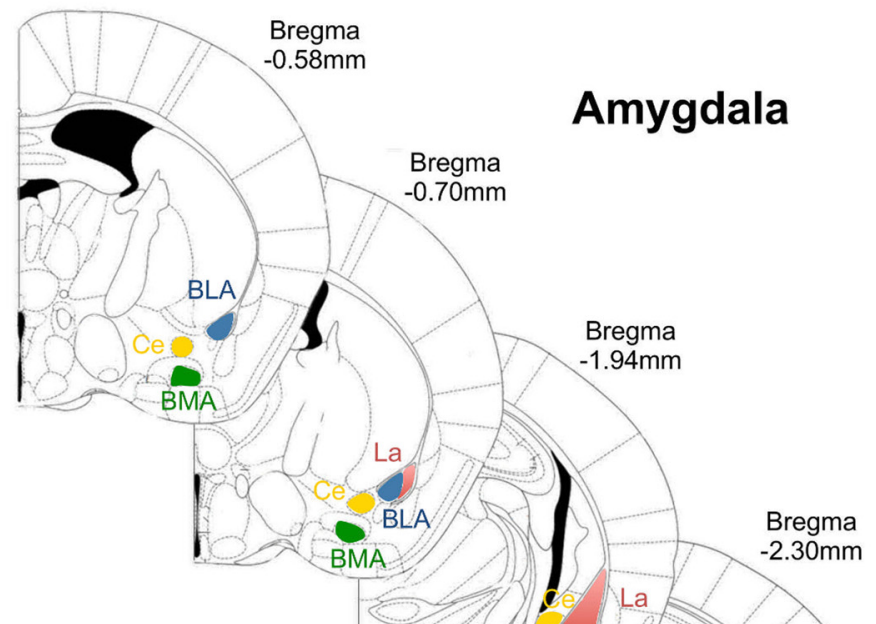

D

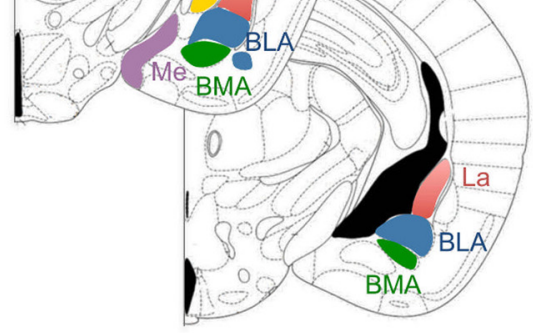

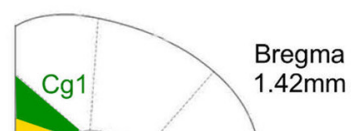

cg

$\operatorname{Cg} 1$

Bregma $2.34 \mathrm{~mm}$

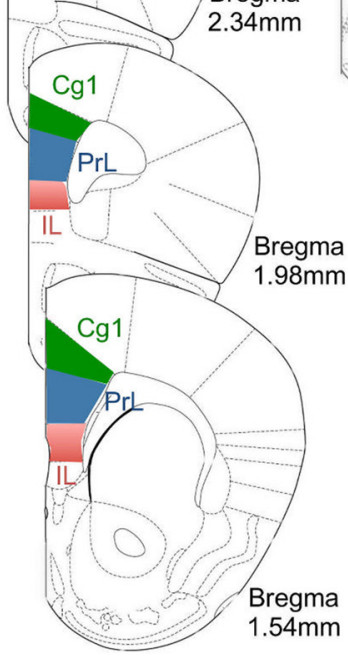

\section{Prefrontal Cortex}

Figure 4. Volumetric analysis. Treatment, rearing, and the interaction of both treatments influenced the volume of the amygdala and the PFC. Although the total volume of both regions was not significantly affected $(\boldsymbol{A})$, the volume of some nuclei of the amygdala $(\boldsymbol{B}, \boldsymbol{C})$ and some regions of the PFC $(\boldsymbol{D}, \boldsymbol{E})$ was affected by treatment (BMA, Cg1), rearing (BLA, IL), or their interaction (Ce, Cg1). Horizontal 
continued

lines in graphs represent trends and statistically significant effects of MK801 treatment (black), rearing (gray), or interaction (gray, dashed) in a two-way ANOVA. \# $0.1>p>0.05, * p<0.05, * * p<0.01, * * * p<0.001$. Colored symbols in bars represent trends and statistically significant differences among groups after post hoc analysis: \# $0.1>p>0.05, * p<0.05, * * p<0.01$, ***p $<0.001$. $\boldsymbol{B}$, $\boldsymbol{D}$, Schematic representations of the regions that were measured in our volumetric study (amygdala: all brain slices from bregma -0.58 to $-2.30 \mathrm{~mm}$; PFC: all brain slices from bregma +2.96 to $-0.22 \mathrm{~mm}$ ).

Table 3. Summary of results (part II)

\begin{tabular}{|c|c|c|c|c|c|c|}
\hline Parameter & \multicolumn{3}{|c|}{ Main effects (two-way ANOVA) } & \multicolumn{3}{|c|}{ Group differences (from NaCl-Social) } \\
\hline \multicolumn{7}{|c|}{ Dendritic spines } \\
\hline 50 & - & - & $\mathfrak{J}^{(28)}$ & - & - & - \\
\hline 100 & - & - & - & $\mathrm{n} / \mathrm{a}$ & $\mathrm{n} / \mathrm{a}$ & $\mathrm{n} / \mathrm{a}$ \\
\hline 150 & - & $\boldsymbol{J}^{(29)}$ & - & $\mathrm{n} / \mathrm{a}$ & $\mathrm{n} / \mathrm{a}$ & $\mathrm{n} / \mathrm{a}$ \\
\hline \multicolumn{7}{|c|}{ Structure of interneurons (Fig. 6) } \\
\hline \multicolumn{7}{|c|}{ Dendritic arborization } \\
\hline \multicolumn{7}{|c|}{ Amygdala } \\
\hline 20 & - & $\#^{(31)}$ & $\mathfrak{J}^{(32)}$ & - & - & - \\
\hline 40 & - & $\mathfrak{J}^{(33)}$ & $\mathcal{J}^{(34)}$ & - & - & $\uparrow^{*}$ \\
\hline 60 & $\mathfrak{J}^{(35)}$ & $\boldsymbol{J}^{(36)}$ & $\mathfrak{J}^{(37)}$ & - & - & $\uparrow * * *$ \\
\hline 160 & - & - & - & $\mathrm{n} / \mathrm{a}$ & $\mathrm{n} / \mathrm{a}$ & $\mathrm{n} / \mathrm{a}$ \\
\hline Total & $\mathfrak{N}^{(48)}$ & $\mathfrak{S}^{(49)}$ & $\mathfrak{S}^{(50)}$ & - & - & $\uparrow * * *$ \\
\hline \multicolumn{7}{|l|}{ PFC } \\
\hline 20 & - & - & - & $\mathrm{n} / \mathrm{a}$ & $\mathrm{n} / \mathrm{a}$ & $\mathrm{n} / \mathrm{a}$ \\
\hline 40 & - & - & - & $\mathrm{n} / \mathrm{a}$ & $\mathrm{n} / \mathrm{a}$ & $\mathrm{n} / \mathrm{a}$ \\
\hline 60 & - & - & - & $\mathrm{n} / \mathrm{a}$ & $\mathrm{n} / \mathrm{a}$ & $\mathrm{n} / \mathrm{a}$ \\
\hline 80 & - & - & - & $\mathrm{n} / \mathrm{a}$ & $\mathrm{n} / \mathrm{a}$ & $\mathrm{n} / \mathrm{a}$ \\
\hline 100 & - & - & - & $\mathrm{n} / \mathrm{a}$ & $\mathrm{n} / \mathrm{a}$ & $\mathrm{n} / \mathrm{a}$ \\
\hline 120 & - & - & - & $\mathrm{n} / \mathrm{a}$ & $\mathrm{n} / \mathrm{a}$ & $\mathrm{n} / \mathrm{a}$ \\
\hline 140 & - & - & - & $\mathrm{n} / \mathrm{a}$ & $\mathrm{n} / \mathrm{a}$ & $\mathrm{n} / \mathrm{a}$ \\
\hline 160 & - & - & - & $n / a$ & $n / a$ & $\mathrm{n} / \mathrm{a}$ \\
\hline Total & - & - & - & $\mathrm{n} / \mathrm{a}$ & $\mathrm{n} / \mathrm{a}$ & $\mathrm{n} / \mathrm{a}$ \\
\hline \multicolumn{7}{|c|}{ Dendritic spines } \\
\hline \multicolumn{7}{|c|}{ Amygdala } \\
\hline 50 & - & - & - & $\mathrm{n} / \mathrm{a}$ & $\mathrm{n} / \mathrm{a}$ & $\mathrm{n} / \mathrm{a}$ \\
\hline 100 & - & - & - & $\mathrm{n} / \mathrm{a}$ & $\mathrm{n} / \mathrm{a}$ & $\mathrm{n} / \mathrm{a}$ \\
\hline 150 & - & $\#^{(51)}$ & $\#^{(52)}$ & $\mathrm{n} / \mathrm{a}$ & $\mathrm{n} / \mathrm{a}$ & $\mathrm{n} / \mathrm{a}$ \\
\hline Total & - & - & - & $\mathrm{n} / \mathrm{a}$ & $\mathrm{n} / \mathrm{a}$ & $\mathrm{n} / \mathrm{a}$ \\
\hline \multicolumn{7}{|l|}{ PFC } \\
\hline 50 & $\#^{(53)}$ & $\mathfrak{J}^{(54)}$ & $\#^{(55)}$ & $\mathrm{n} / \mathrm{a}$ & $\mathrm{n} / \mathrm{a}$ & $\mathrm{n} / \mathrm{a}$ \\
\hline 100 & $\mathfrak{J}^{(56)}$ & $\mathfrak{J}^{(57)}$ & $\mathcal{J}^{(58)}$ & $\uparrow^{*}$ & $\uparrow^{* * *}$ & $\uparrow^{* * *}$ \\
\hline 150 & $\mathfrak{J}^{(59)}$ & $J^{(60)}$ & - & $\mathrm{n} / \mathrm{a}$ & $\mathrm{n} / \mathrm{a}$ & n/a \\
\hline Total & $\mathcal{J}^{(61)}$ & $\mathfrak{J}^{(62)}$ & $\mathfrak{J}^{(63)}$ & $\uparrow^{* * *}$ & $\uparrow * * *$ & $\uparrow * * *$ \\
\hline
\end{tabular}

Symbols: $(\mathcal{})$ statistically significant effect (two-way ANOVA); (-) no statistically significant effect (two-way ANOVA) or difference from NaCl-Social group (post hoc); $(\uparrow)$ increase; (n/a) not applicable; $(\downarrow)$ decrease; $* p<0.05 ; * * p<0.01 ; * * * p<0.001 ; \# 0.10 \geq p \geq 0.05$.

$F$ and $p$ values: $(28) F_{(1,15)}=6.29, p=0.024 ;(29) F_{(1,15)}=4.88, p=0.043 ;(30) F_{(1,18)}=4.90, p=0.043(31) F_{(1,19)}=3.81, p=0.066 ;(32) F_{(1,19)}=4.72, p$ $=0.043 ;(33) F_{(1,19)}=9.02, p=0.007 ;(34) F_{(1,19)}=12.58, p=0.002 ;(35) F_{(1,18)}=7.53, p=0.013 ;(36) F_{(1,18)}=23.53, p=12.8 \times 10-5 ;(37) F_{(1,18)}=$ $12.62, p=0.002 ;(38) F_{(1,19)}=4.64, p=0.044 ;(39) F_{(1,19)}=6.55, p=0.019 ;(40) F_{(1,19)}=10.23, p=0.005 ;(41) F_{(1,20)}=4.43, p=0.048 ;(42) F_{(1,20)}=8.79, p=$ $0.008 ;(43) F_{(1,20)}=3.27, p=0.086 ;(44) F_{(1,20)}=5.73, p=0.027 ;(45) F_{(1,20)}=5.32, p=0.032 ;(46) F_{(1,20)}=14.63, p=0.0011 ;(47) F_{(1,20)}=4.34, p=$ $0.050 ;(48) F_{(1,20)}=8.31, p=0.009 ;(49) F_{(1,20)}=14.29, p=0.001 ;(50) F_{(1,20)}=18.23, p=37.5 \times 10^{-5} ;(51) F_{(1,22)}=3.79, p=0.064 ;(52) F_{(1,22)}=3.34, p$ $=0.081 ;(53) F_{(1,22)}=3.74, p=0.066 ;(54) F_{(1,22)}=4.53, p=0.045 ;(55) F_{(1,22)}=3.31, p=0.083 ;(56) F_{(1,22)}=11.72, p=0.002 ;(57) F_{(1,22)}=5.50, p=$ $0.029 ;(58) F_{(1,22)}=5.18, p=0.033 ;(59) F_{(1,22)}=5.50, p=0.028 ;(60) F_{(1,22)}=7.43, p=0.012 ;(61) F_{(1,22)}=21.08, p=14.2 \times 10^{-5} ;(62) F_{(1,22)}=6.27, p$ $=0.020$; $(63) F_{(1,22)}=10.18, p=0.004$. 

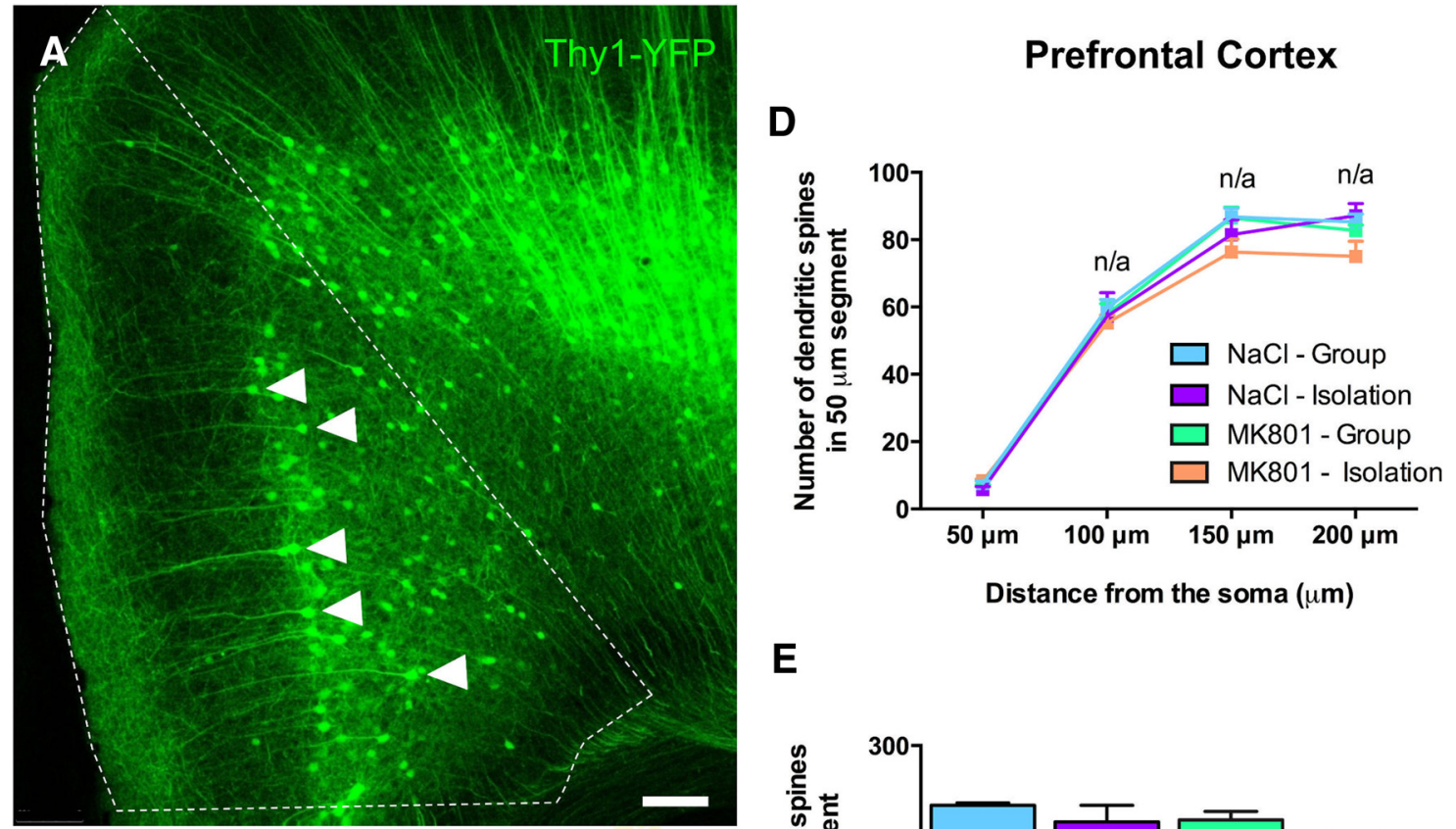

$\mathbf{E}$
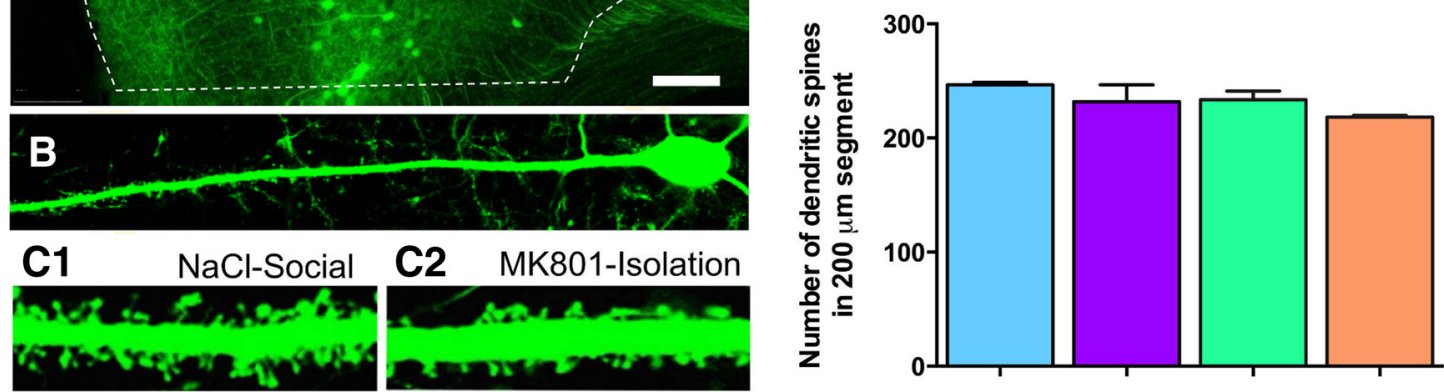

Figure 5. Structural analysis of pyramidal neurons. A, Panoramic view of the PFC of THY1-YFP expressing mice. Arrowheads point to fluorescent pyramidal neurons. B, Representative confocal image of a pyramidal neuron from these animals. $\mathbf{C 1}(\mathrm{NaCl}-\mathrm{Group})$ and C2 (MK801-Isolation) represent sections of the spiny apical dendrites of these pyramidal neurons. $\boldsymbol{D}, \boldsymbol{E}$, Graphs showing the results of the analysis of dendritic spine density. $\boldsymbol{D}$, The segmented analysis of the spine densities only showed a significant interaction effect in the first segment (0-50 $\mu \mathrm{m}$ of distance from the soma; Table 3) but no statistically significant differences among groups where observed after post hoc comparison. Despite the significant effects of treatment or rearing in some of the other segments (Table 3 ), the interaction (two-way ANOVA) was not significant in any of them and, therefore, post hoc comparisons were not applicable (n/a). $\boldsymbol{E}$, No statistical significant effects of treatment, rearing, or their interaction (two-way ANOVA) were observed when analyzing the spines density of the total length of the dendrite $(200 \mu \mathrm{m})$. Scale bars: $\boldsymbol{A}, 100 \mu \mathrm{m} ; \boldsymbol{B}, 20 \mu \mathrm{m} ; \mathbf{C 1}, \mathbf{C 2}, 2.5 \mu \mathrm{m}$.

nonsignificant because of the lack of interaction between factors (Fig. 5E).

Previous work from different laboratories has shown that the structure of interneurons is also susceptible to change in different paradigms, including chronic stress (Gilabert-Juan et al. 2011, 2013b). For this reason, we have also evaluated the structure of a subpopulation of these inhibitory neurons (Oliva et al. 2000). Treatment, rearing, and their interaction affected the total number of dendritic intersections in interneurons of the amygdala and the density of dendritic spines in interneurons of the PFC (Fig.6; Table 3). In particular, interneurons from double-hit mice showed significantly increased arborization in the amygdala (Fig.6B1,B2,D,E) and significantly increased density of dendritic spines in the PFC (Fig. $6 \mathrm{~J} 1, \mathrm{~J} 2, \mathrm{M}, \mathrm{N})$ compared with the control group.

\section{Decreased E/I Ratio in the Amygdala but Increased in the PFC}

To have another readout of the putative alterations in inhibitory networks and the balance of excitatory versus inhibitory neurotransmission, we have studied with immunohistochemistry the expression of the GABA and glutamate vesicular transporters (VGAT and VGLUT1). Almost all nuclei/regions of the amygdala and PFC showed significant effects of treatment, rearing, or their interaction when analyzing the density of VGLUT1 and VGAT expressing puncta and E/I ratio (Table 4). Regarding excitatory puncta (VGLUT1), double-hit animals showed increased density in the La and Me nuclei of the amygdala (Fig. $7 A 1, A 2)$ but no changes in any of the regions of the PFC (Fig. 7B1,B2). These animals also showed decreased density of VGAT puncta in the $\mathrm{Cg} 1-\mathrm{Cg} 2$ region of the PFC (Fig. 7B1,B3 ). The E/I ratio was significantly increased in the PFC of double-hit animals (IL + PrL; (Fig. 7B4).

\section{Expression of GAD67, SYN, and PSA-NCAM}

The differences that we have found in the structure of interneurons and in the E/I ratio prompted us to study the expression of molecules related to inhibitory neurotransmission and to the plasticity of interneuronal networks, such as the polysialylated form of the neural cell adhesion 


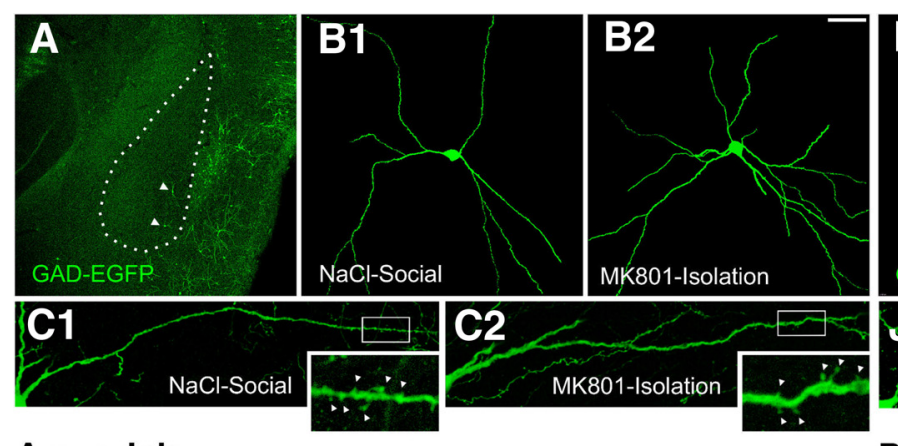

Amygdala

D

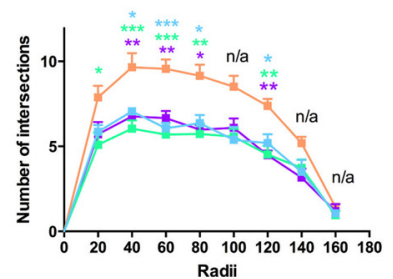

F

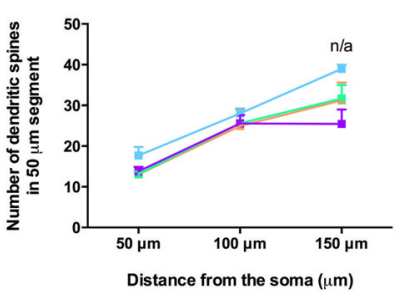

E

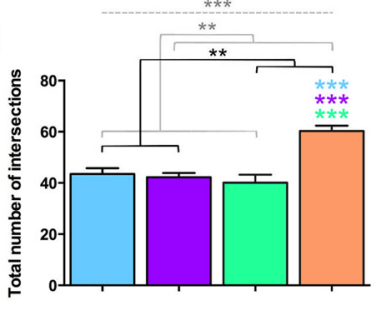

G

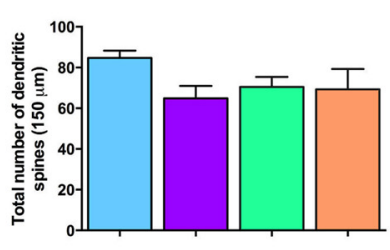

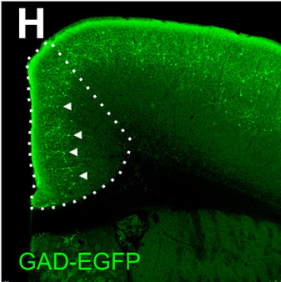

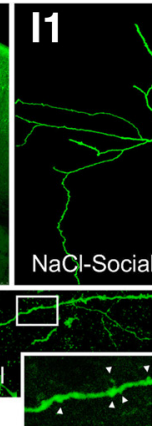

Prefrontal Cortex

K

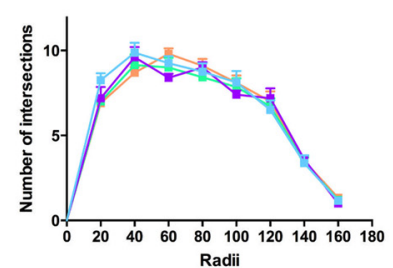

M

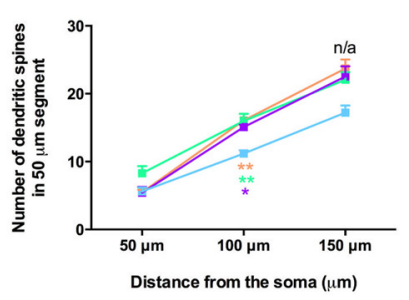

L

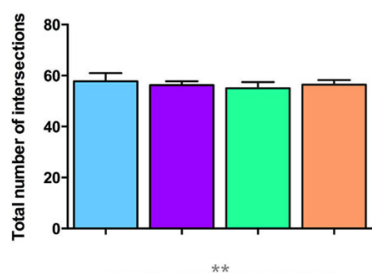

$\mathbf{N}$

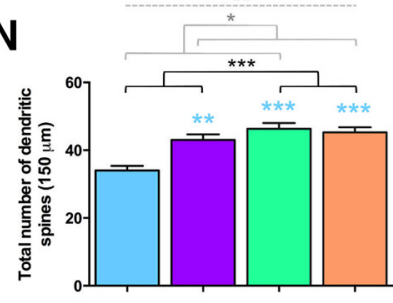

- NaCl-Social - - NaCl-Isolation - MK801-Social - - MK801-Isolation

Figure 6. Structural analysis of interneurons. Panoramic view of the amygdala $(\boldsymbol{A})$ and PFC $(\boldsymbol{H})$ of GIN mice. B1, B2, /1, I2, Representative 3D reconstructions of the dendritic arbor of GAD-EGFP expressing interneurons. Double-hit mice showed increased dendritic arborization (number of intersections in the Sholl analysis) in interneurons form the amygdala (D, $\boldsymbol{E})$ but not from the PFC $(\boldsymbol{K}, \boldsymbol{L}) . \mathbf{C 1}, \mathbf{C 2}, \boldsymbol{J 1}, \boldsymbol{J} 2$, Representative images of spiny dendrites from GAD-EGFP expressing interneurons. Insets are magnified views of the squared sections of their respective images. Arrowheads point to dendritic spines. Analysis of the dendritic spines showed increased density in the PFC $(\boldsymbol{M}, \boldsymbol{N})$ but not in the amygdala $(\boldsymbol{F}, \boldsymbol{G})$ of double-hit mice. Horizontal lines in graphs $(\boldsymbol{E}, \boldsymbol{N})$ represent statistically significant effects of MK801 treatment (black), rearing (gray), or interaction (gray, dashed) in a two-way ANOVA. $* p<0.05$, $* * p<0.01, * * * p<0.001$. Colored symbols $(\boldsymbol{D}, \boldsymbol{E}, \boldsymbol{M}, \boldsymbol{N})$ represent statistically significant differences among groups after post hoc analysis: $* p<0.05, * * p<0.01, * * * p<0.001$. If the interaction (two-way ANOVA) was not significant, post hoc comparisons were not applicable (n/a). Scale bars: $\boldsymbol{A}, \boldsymbol{H}, 800 \mu \mathrm{m} ; \boldsymbol{B}, \boldsymbol{I}, 40 \mu \mathrm{m} ; \boldsymbol{C}, \boldsymbol{J}, 14 \mu \mathrm{m} ; \boldsymbol{C}, \boldsymbol{J}$ (insets), $2 \mu \mathrm{m}$.

molecule (PSA-NCAM; Nacher et al. 2013). GAD67 protein expression in the amygdala was significantly influenced by rearing (increased as a consequence of social isolation) but double-hit animals failed to show significant differences compared with the control group (Table 5; Fig. $8 A)$. Synaptophysin (SYN) protein expression in both regions and GAD67 expression in the PFC were not affected by any experimental condition (Table 5; Fig. 8A,B). PSANCAM expression was influenced by rearing (decreased expression in the amygdala after social isolation) and treatment (after MK-801, increased expression in the amygdala and decreased expression in the PFC) but not by their interaction (Table 5; Fig. $8 B, D$ ).

\section{Rearing Influences BDNF, CB1-R, and St8SialV Gene Expression}

We have also studied the expression of different genes involved in the development and regulation of inhibitory networks, including the enzymes responsible for PSA synthesis. Among all the studied genes, a significant effect of rearing was found when studying BDNF (increased after social isolation) and ST8SialV mRNA expression (decreased after social isolation) in the PFC and CB1-R mRNA expression (increased after social isolation) in the amygdala (Table 5; Fig. 8D-l).

\section{Number of PNNs and PV-Expressing Neurons Surrounded by PNNs}

Different components of the extracellular matrix can play a role in the $E / I$ imbalance and the remodeling of inhibitory networks observed in our study. Of particular interest are PNNs, which are abundant around PVexpressing interneurons (Härtig et al. 1992). The composition of these PNN is regulated dynamically in response to aversive experiences, such as fear or stress, and alterations in the expression of PNNs have been observed in the PFC of schizophrenic patients (Berretta et al. 2015). In our study, effects of treatment, isolation, and their inter- 
Table 4. Summary of results (part III)

\begin{tabular}{|c|c|c|c|c|c|c|}
\hline \multirow[b]{2}{*}{ Parameter } & \multicolumn{3}{|c|}{ Main effects (two-way ANOVA) } & \multicolumn{3}{|c|}{ Group differences (from NaCl-Social) } \\
\hline & Treatment & Rearing & Interaction & $\mathrm{NaCl}$-Isolation & MK801-Social & MK801-Isolation \\
\hline \multicolumn{7}{|c|}{ Density of neuropil puncta (Fig. 7) } \\
\hline \multicolumn{7}{|c|}{ VGLUT1 (Amygdala) } \\
\hline Central & - & - & - & $\mathrm{n} / \mathrm{a}$ & $\mathrm{n} / \mathrm{a}$ & $\mathrm{n} / \mathrm{a}$ \\
\hline Lateral & $\mathfrak{J}^{(64)}$ & $\mathfrak{J}^{(65)}$ & $\mathfrak{J}^{(66)}$ & - & - & $\uparrow^{*}$ \\
\hline Basolateral & - & - & - & $\mathrm{n} / \mathrm{a}$ & $\mathrm{n} / \mathrm{a}$ & $n / a$ \\
\hline Basomedial & $\mathfrak{S}^{(67)}$ & $\mathfrak{J}^{(68)}$ & $\#^{(69)}$ & $\mathrm{n} / \mathrm{a}$ & $\mathrm{n} / \mathrm{a}$ & $\mathrm{n} / \mathrm{a}$ \\
\hline Medial & $\#^{(70)}$ & $\mathfrak{J}^{(71)}$ & $\mathcal{J}^{(72)}$ & - & - & $\uparrow^{*}$ \\
\hline \multicolumn{7}{|l|}{ VGLUT1 (PFC) } \\
\hline $\mathrm{IL}+\mathrm{PrL}$ & - & - & - & $\mathrm{n} / \mathrm{a}$ & $\mathrm{n} / \mathrm{a}$ & $\mathrm{n} / \mathrm{a}$ \\
\hline $\mathrm{Cg} 1+\mathrm{Cg} 2$ & $\mathscr{S}^{(73)}$ & $\mathfrak{J}^{(74)}$ & $\#^{(75)}$ & $\mathrm{n} / \mathrm{a}$ & $\mathrm{n} / \mathrm{a}$ & $\mathrm{n} / \mathrm{a}$ \\
\hline \multicolumn{7}{|c|}{ VGAT (Amygdala) } \\
\hline Central & - & $\#^{(76)}$ & - & $\mathrm{n} / \mathrm{a}$ & $\mathrm{n} / \mathrm{a}$ & $\mathrm{n} / \mathrm{a}$ \\
\hline Lateral & - & $\mathfrak{S}^{(77)}$ & - & $\mathrm{n} / \mathrm{a}$ & $\mathrm{n} / \mathrm{a}$ & $\mathrm{n} / \mathrm{a}$ \\
\hline Basolateral & $\#^{(78)}$ & $\#^{(79)}$ & $\#^{(80)}$ & $\mathrm{n} / \mathrm{a}$ & $\mathrm{n} / \mathrm{a}$ & $\mathrm{n} / \mathrm{a}$ \\
\hline Basomedial & $\#^{(81)}$ & $\mathfrak{J}^{(82)}$ & - & $\mathrm{n} / \mathrm{a}$ & $\mathrm{n} / \mathrm{a}$ & $\mathrm{n} / \mathrm{a}$ \\
\hline Medial & $\#^{(83)}$ & $\mathfrak{J}^{(84)}$ & $\#(85)$ & $\mathrm{n} / \mathrm{a}$ & $\mathrm{n} / \mathrm{a}$ & $\mathrm{n} / \mathrm{a}$ \\
\hline \multicolumn{7}{|l|}{ VGAT (PFC) } \\
\hline $\mathrm{IL}+\mathrm{PrL}$ & $\#^{(86)}$ & $\#^{(87)}$ & $\mathcal{J}^{(88)}$ & - & $\uparrow^{*}$ & - \\
\hline $\mathrm{Cg} 1+\mathrm{Cg} 2$ & - & $\mathcal{J}^{(89)}$ & - & $\mathrm{n} / \mathrm{a}$ & $\mathrm{n} / \mathrm{a}$ & $\mathrm{n} / \mathrm{a}$ \\
\hline \multicolumn{7}{|c|}{ E/I Balance (Fig. 7) } \\
\hline \multicolumn{7}{|l|}{ Amygdala } \\
\hline Central & - & - & - & $\mathrm{n} / \mathrm{a}$ & $\mathrm{n} / \mathrm{a}$ & $\mathrm{n} / \mathrm{a}$ \\
\hline Lateral & $\#^{(90)}$ & $\mathfrak{J}^{(91)}$ & - & $\mathrm{n} / \mathrm{a}$ & $\mathrm{n} / \mathrm{a}$ & $\mathrm{n} / \mathrm{a}$ \\
\hline Basolateral & - & $\mathfrak{J}^{(92)}$ & - & $\mathrm{n} / \mathrm{a}$ & $\mathrm{n} / \mathrm{a}$ & $\mathrm{n} / \mathrm{a}$ \\
\hline Basomedial & - & - & - & $\mathrm{n} / \mathrm{a}$ & $\mathrm{n} / \mathrm{a}$ & $\mathrm{n} / \mathrm{a}$ \\
\hline Medial & - & - & - & $\mathrm{n} / \mathrm{a}$ & $\mathrm{n} / \mathrm{a}$ & $\mathrm{n} / \mathrm{a}$ \\
\hline \multicolumn{7}{|l|}{ PFC } \\
\hline $\mathrm{IL}+\operatorname{PrL}$ & $\#^{(93)}$ & $\mathfrak{J}^{(94)}$ & $\mathcal{S}^{(95)}$ & - & - & $\uparrow^{*}$ \\
\hline $\mathrm{Cg} 1+\mathrm{Cg} 2$ & $\mathcal{J}^{(96)}$ & $\mathfrak{J}^{(97)}$ & - & $\mathrm{n} / \mathrm{a}$ & $\mathrm{n} / \mathrm{a}$ & $\mathrm{n} / \mathrm{a}$ \\
\hline
\end{tabular}

Symbols: $(\mathcal{})$ statistically significant effect (two-way ANOVA); (-) no statistically significant effect (two-way ANOVA) or difference from NaCl-Social group (post hoc); $(\uparrow$ ) increase; (n/a) not applicable; $(\downarrow)$ decrease; $* p<0.05 ; * * p<0.01 ; * * * p<0.001 ; \# 0.10 \geq p \geq 0.05$.

$F$ and $p$ values: $(64) F_{(1,29)}=4.58, p=0.041 ;(65) F_{(1,29)}=7.12, p=0.012 ;(66) F_{(1,29)}=4.20, p=0.049 ;(67) F_{(1,28)}=4.89, p=0.036 ;(68) F_{(1,28)}=6.08, p$ $=0.020 ;(69) F_{(1,28)}=3.17, p=0.086 ;(70) F_{(1,29)} \stackrel{(1,29)}{=} 3.74, p=0.063 ;(71) F_{(1,29)} \stackrel{2}{=} 4.32, p=0.047 ;(72) F_{(1,29)}=5.01, p=0.033 ;(73) F_{(1,19)}=6.31, p=$ $0.021 ;(74) F_{(1,19)}=8.44, p=0.009 ;(75) F_{(1,19)}=3.54, p=0.075 ;(76) F_{(1,29)}=3.45, p=0.074 ;(77) F_{(1,28)}=5.28, p=0.029 ;(78) F_{(1,29)}=3.09, p=0.089$; (79) $F_{(1,29)}=3.88, p=0.058 ;(80) F_{(1,29)}=2.91, p=0.097 ;(81) F_{(1,29)}=3.16, p=0.086 ;(82) F_{(1.29)}=4.29, p=0.047 ;(83) F_{(1.29)}=3.47, p=0.073 ;(84)$ $F_{(1,29)}=5.88, p=0.022 ;(85) F_{(1,29)}=3.05, p=0.091 ;(86) F_{(1,18)}=3.75, p=0.069 ;(87) F_{(1,18)}=3.88, p=0.065 ;(88) F_{(1,18)}=6.53, p=0.020 ;(89) F_{(1,19)}=$ $21.12, p=2 \times 10^{-4} ;(90) F_{(1,29)}=3.55, p=0.070 ;(91) F_{(1,29)}=9.01, p=0.005 ;(92) F_{(1,28)}=6.75, p=0.015 ;(93) F_{(1,18)}=3.93, p=0.063 ;(94) F_{(1,18)}=$ 6.18, $p=0.023 ;(95) F_{(1,18)}=6.39, p=0.021 ;(96) F_{(1,18)}=10.72, p=0.004 ;(97) F_{(1,18)} \stackrel{1}{=} 8.33, p=0.0098$.

action were found in different regions of the MPFC and the amygdala. Specifically, in the infralimbic cortex, both isolated, and especially MK-801-treated animals, showed a significant increase in the number of PV-expressing neurons, PNNs, and PV-expressing neurons surrounded by PNNs (only MK-801; Table 6; Fig. 9). By contrast, in this region there was a tendency for a decrease in these parameters in the double-hit mice.

\section{Discussion}

In the present study, we report alterations in behavior, neuronal structural plasticity, and $E / I$ neurotransmission in mice subjected to chronic early-life stress, consisting in a social isolation rearing from the age of weaning until adulthood. A group of animals (double-hit) was also subjected to a perinatal injection of the NMDAR antagonist MK801 to interfere with the last stages of neocortical development: the activation of the NMDA receptor is essential for neuronal differentiation, migration, and survival (Jansson and Åkerman, 2014) and perinatal treatments with NMDAR antagonists trigger apoptosis, specially in the fron- tal neocortex (lkonomidou et al. 1999; Wang and Johnson, 2005).

Both interventions, isolation and MK801 treatment, have been considered animal models for schizophrenia. We have found that, especially, the isolation rearing induces a wide spectrum of alterations, including changes in neurochemical, behavioral, and structural parameters. These changes affect particularly interneurons and some of them are significant when this aversive experience is combined with the neurodevelopmental intervention. These effects are the consequence of prolonged isolation stress during a period in which the circuits are already stablished, although they still display a high degree of plasticity. Alterations on the structure and neurotransmission of interneurons can be induced even in young-adult animals when they are subjected to chronic stress (Gilabert-Juan et al. 2011). By contrast, the single injection of MK801 in P7 is a procedure that disturbs acutely ongoing neurodevelopmental processes, particularly in the frontal cortex, such as neuronal migration, neurite extension, or synaptogenesis. This is an important time 
A1

Amygdala
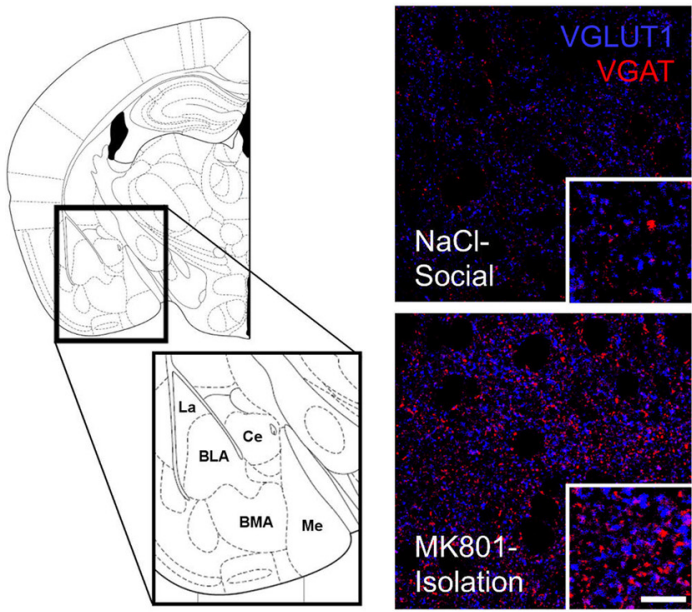

A2

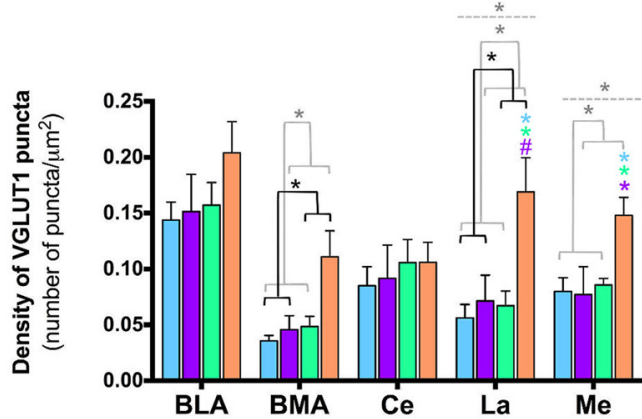

A3

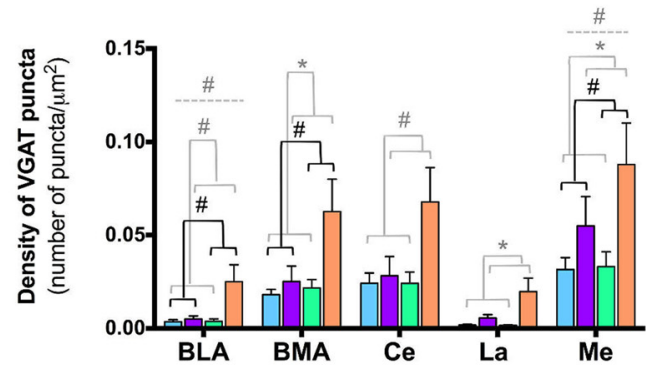

A4

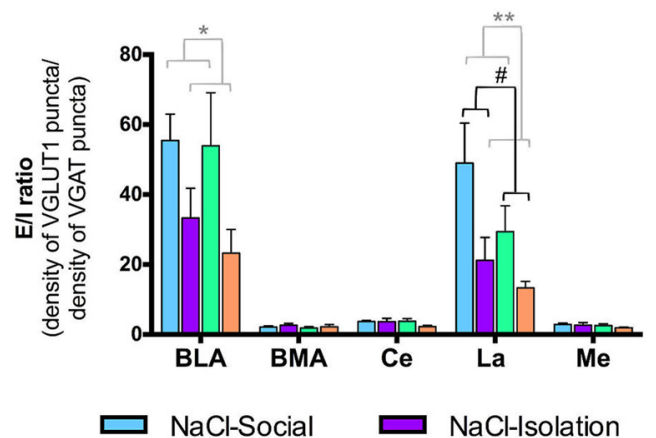

\section{B1} Prefrontal Cortex
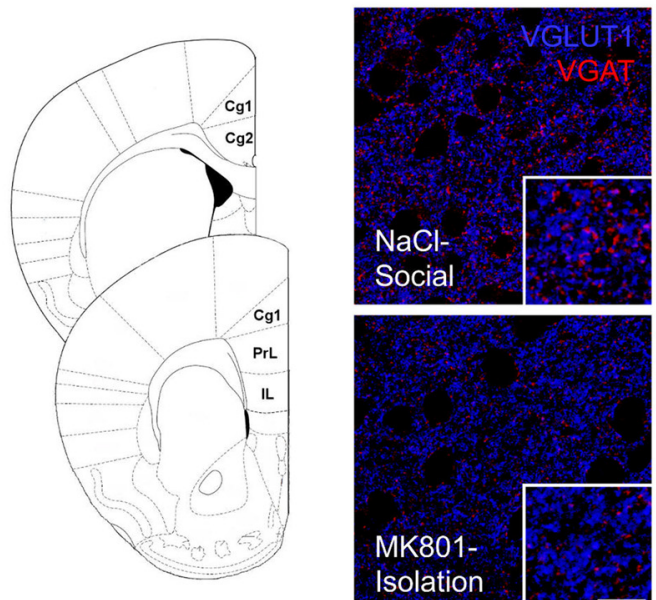

B2

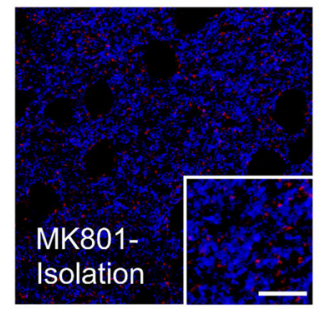

MK801-

solation

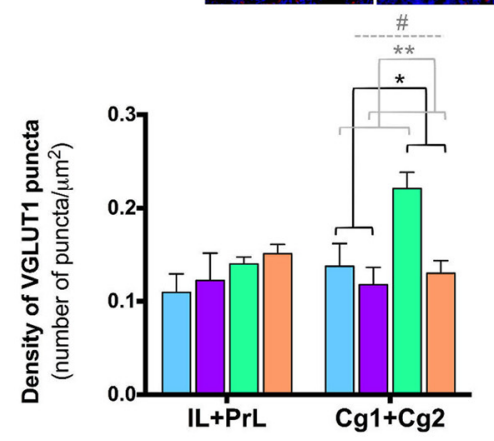

B3

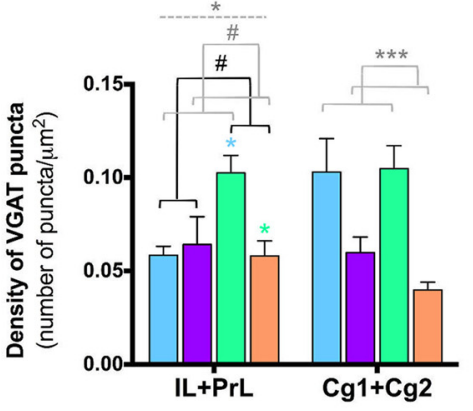

B4

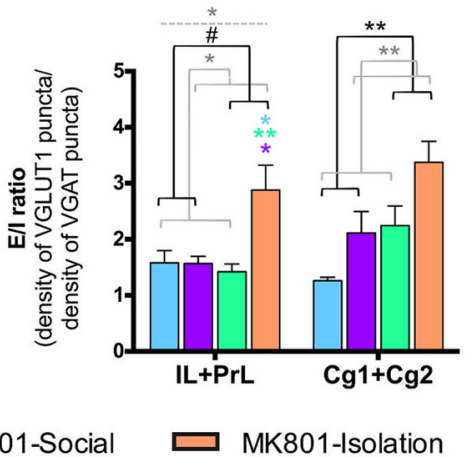

Figure 7. Excitatory and inhibitory neurotransmission. Schematic view of all the analyzed regions (A1, amygdala; B1, PFC). Right, Representative confocal images of excitatory (blue, VGLUT1) and inhibitory (red, VGAT) puncta in the neuropil of NaCl-Social and MK801-Isolated animals. Scale bars: images, $16 \mu \mathrm{m}$; insets, $6 \mu \mathrm{m}$. Significant differences in VGLUT1 puncta density (A2, B2), VGAT puncta density $(\mathbf{A 3}, \mathbf{B} 3)$, and $E / /$ ratio $(\boldsymbol{A 4}, \mathbf{B} 4)$ among groups were observed. Horizontal lines in graphs represent trends and statistically significant effects of MK801 treatment (black), rearing (gray), or interaction (gray, dashed) in a two-way ANOVA. \# $0.1>$ $p>0.05, * p<0.05, * * p<0.01, * * * p<0.001$. Colored symbols in bars represent trends and statistically significant differences among groups after post hoc analysis: \# $0.1>p>0.05, * p<0.05, * * p<0.01, * * * p<0.001$. 
Table 5. Summary of results (part IV)

\begin{tabular}{|c|c|c|c|c|c|c|}
\hline \multirow{3}{*}{$\begin{array}{l}\text { Parameter } \\
\text { Protein expression (Fig.7) }\end{array}$} & \multicolumn{3}{|c|}{ Main effects (two-way ANOVA) } & \multicolumn{3}{|c|}{ Group differences (from NaCl-Social) } \\
\hline & Treatment & Rearing & Interaction & $\mathrm{NaCl}$-Isolation & MK801-Social & MK801-Isolation \\
\hline & & & & & & \\
\hline \multicolumn{7}{|c|}{ GAD67 } \\
\hline Amygdala & - & $\mathscr{J}^{(98)}$ & - & $\mathrm{n} / \mathrm{a}$ & $\mathrm{n} / \mathrm{a}$ & $\mathrm{n} / \mathrm{a}$ \\
\hline PFC & - & - & - & $\mathrm{n} / \mathrm{a}$ & $\mathrm{n} / \mathrm{a}$ & $\mathrm{n} / \mathrm{a}$ \\
\hline \multicolumn{7}{|l|}{ SYN } \\
\hline Amygdala & - & - & - & $\mathrm{n} / \mathrm{a}$ & $\mathrm{n} / \mathrm{a}$ & $\mathrm{n} / \mathrm{a}$ \\
\hline PFC & - & - & - & $\mathrm{n} / \mathrm{a}$ & $\mathrm{n} / \mathrm{a}$ & $\mathrm{n} / \mathrm{a}$ \\
\hline \multicolumn{7}{|l|}{ PSA-NCAM } \\
\hline Amygdala & $\mathcal{J}^{(99)}$ & $\mathcal{J}^{(100)}$ & $\#^{(101)}$ & $\mathrm{n} / \mathrm{a}$ & $\mathrm{n} / \mathrm{a}$ & $\mathrm{n} / \mathrm{a}$ \\
\hline PFC & $\mathfrak{J}^{(102)}$ & - & - & $n / a$ & $\mathrm{n} / \mathrm{a}$ & $\mathrm{n} / \mathrm{a}$ \\
\hline \multicolumn{7}{|c|}{ Gene expression (Fig.7) } \\
\hline \multicolumn{7}{|c|}{ GAD67 } \\
\hline Amygdala & - & - & - & $\mathrm{n} / \mathrm{a}$ & $\mathrm{n} / \mathrm{a}$ & $\mathrm{n} / \mathrm{a}$ \\
\hline PFC & $\#^{(103)}$ & - & - & $\mathrm{n} / \mathrm{a}$ & $\mathrm{n} / \mathrm{a}$ & $\mathrm{n} / \mathrm{a}$ \\
\hline \multicolumn{7}{|l|}{ BDNF } \\
\hline Amygdala & - & - & - & $\mathrm{n} / \mathrm{a}$ & $\mathrm{n} / \mathrm{a}$ & $\mathrm{n} / \mathrm{a}$ \\
\hline PFC & - & $\mathcal{J}^{(104)}$ & - & $\mathrm{n} / \mathrm{a}$ & $\mathrm{n} / \mathrm{a}$ & $\mathrm{n} / \mathrm{a}$ \\
\hline \multicolumn{7}{|l|}{ ErbB4 } \\
\hline Amygdala & - & - & $\#^{(105)}$ & $\mathrm{n} / \mathrm{a}$ & $\mathrm{n} / \mathrm{a}$ & $\mathrm{n} / \mathrm{a}$ \\
\hline PFC & - & - & - & $n / a$ & $n / a$ & $\mathrm{n} / \mathrm{a}$ \\
\hline \multicolumn{7}{|l|}{ CB1-R } \\
\hline Amygdala & - & $\mathfrak{S}^{(106)}$ & - & $\mathrm{n} / \mathrm{a}$ & $\mathrm{n} / \mathrm{a}$ & $\mathrm{n} / \mathrm{a}$ \\
\hline PFC & - & - & - & $n / a$ & $n / a$ & $\mathrm{n} / \mathrm{a}$ \\
\hline \multicolumn{7}{|l|}{ ST8Siall } \\
\hline Amygdala & $\#^{(107)}$ & - & - & $\mathrm{n} / \mathrm{a}$ & $\mathrm{n} / \mathrm{a}$ & $\mathrm{n} / \mathrm{a}$ \\
\hline PFC & - & - & - & $n / a$ & $n / a$ & $\mathrm{n} / \mathrm{a}$ \\
\hline \multicolumn{7}{|l|}{ ST8SialV } \\
\hline Amygdala & - & - & - & $n / a$ & $\mathrm{n} / \mathrm{a}$ & $\mathrm{n} / \mathrm{a}$ \\
\hline PFC & $\#^{(108)}$ & $\boldsymbol{J}^{(109)}$ & - & $\mathrm{n} / \mathrm{a}$ & $\mathrm{n} / \mathrm{a}$ & $\mathrm{n} / \mathrm{a}$ \\
\hline
\end{tabular}

Symbols: $(\checkmark)$ statistically significant effect (two-way ANOVA); $(-)$ no statistically significant effect (two-way ANOVA) or difference from NaCl-Social group (post hoc); $(\uparrow)$ increase; (n/a) not applicable; $(\downarrow)$ decrease; $(*) p<0.05 ;(* *) p<0.01 ;(* * *) p<0.001 ;(\#) 0.10 \geq p \geq 0.05$.

$F$ and $p$ values: $(98) F_{(1,19)}=11.74, p=0.003 ;(99) F_{(1.25)}=11.58, p=0.002 ;(100) F_{(1,25)}=107.23, p<10^{-10} ;(101) F_{(1.25)}=4.02, p=0.056 ;(102) F_{(1.32)}=$ 9.863, $p=0.004 ;(103) F_{(1,25)}=3.94, p=0.058 ;(104) F_{(1,26)}=13.51, p=0.001 ;(105) F_{(1,25)}=4.10, p=0.054 ;(106) F_{(1,26)}=5.52, p=0.027 ;(107)$ $F_{(1,20)}=3.07, p=0.095 ;(108) F_{(1,25)}=4.12, p=0.053 ;(109) F_{(1,25)}=5.06, p=0.033$.

point for the maturation of inhibitory circuits. When animals are subjected to both alterations (MK801 injection and social isolation), we observe a cumulative effect, especially on the structure of interneurons. Probably the early effect of MK801 disturbs the construction of interneuronal morphology and connectivity. In animals reared in group, these alterations are probably compensated during infancy and puberty: for instance, in the proportion of PV-expressing neurons surrounded by PNNs in the infralimbic cortex, the significant effects of the MK801 injection appear to be reverted by the social isolation. However, if the animals are subjected to the prolonged isolation stress, the impact of this aversive experience may prevent this compensation. The social isolation stress by itself seems to be enough to produce significant changes in many parameters, but in others, like some anxiety-like and locomotor behaviors, this aversive experience is not enough to render significant alterations. Apparently, these changes only appear when the stressful event operates on a previously altered substrate, such as the subtly modified circuitry of MK801-injected animals.

\section{Behavioral Alterations}

Anxiety, hyperactivity, and working memory deficits are frequently reported in patients suffering from schizophre- nia (Pallanti et al. 2013; Pallanti and Salerno, 2015; Van Snellenberg et al. 2016) and in several animal models of this disease (Jones et al. 2011; Lett et al. 2014). In our study, we used the hole-board apparatus to analyze these behaviors (Karl et al. 2008; Castilla-Ortega et al. 2010; Torres-García et al. 2012). Our results on GIN mice show that rearing in isolation induced anxiety-like behavior and locomotor hyperactivity. Therefore, the functional consequences of the molecular and structural changes affecting only the double-hit GIN mice are not yet clear. The analysis of Thy 1 mice also showed these effects of rearing, but in this strain also revealed significant differences in double-hit animals compared with controls. These behavioral abnormalities may be a long-term consequence of the impairments in brain development that are induced by post-weaning social deprivation, as other authors reported before (Koike et al. 2009; Jones et al. 2011; Hickey et al. 2012; Jiang et al. 2013). No changes in exploratory behavior were observed in any of the strains when measured in the hole-board; this test can be considered as an initial basic screen for working memory (Karl et al. 2008).

Studies on schizophrenia models based on NMDAR hypofunction during early postnatal development have yielded contradictory results; whereas some authors described hyperlocomotion, anxiety-related behaviors, and 
A

GAD67 protein

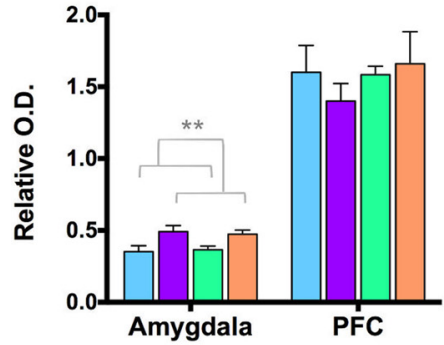

D

GAD67 mRNA

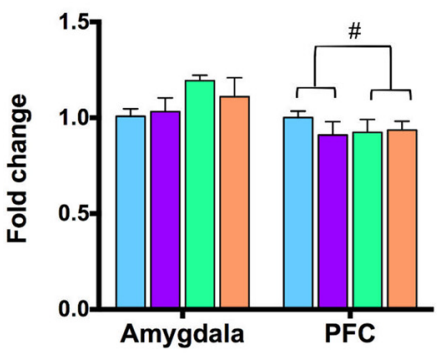

G

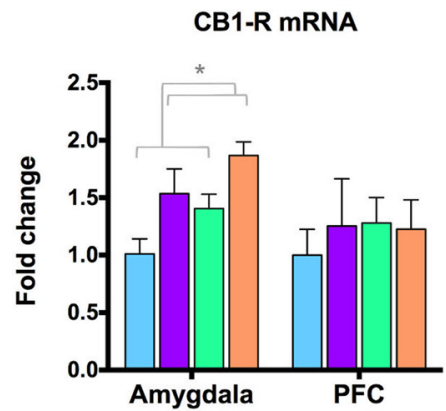

B

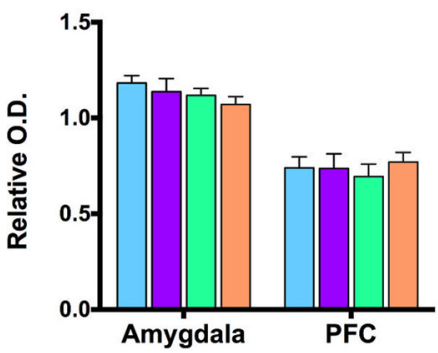

E

BDNF mRNA

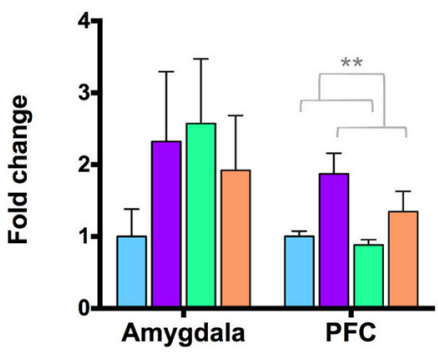

H

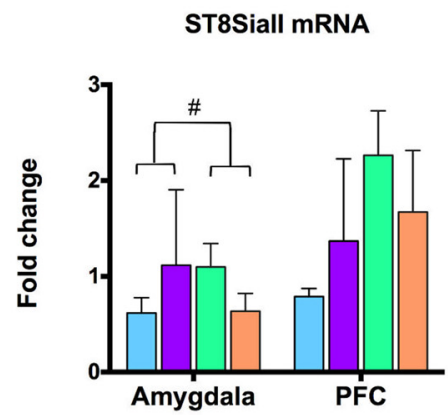

C

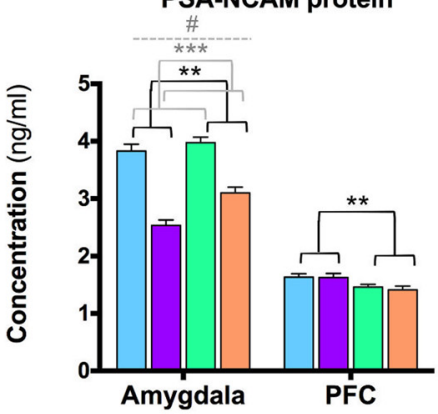

F

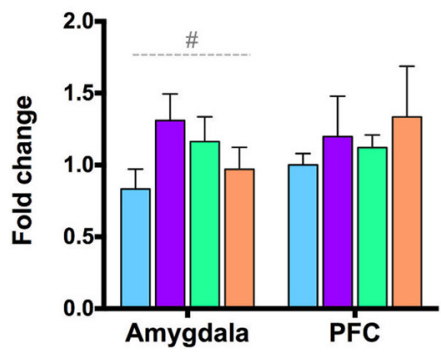

I

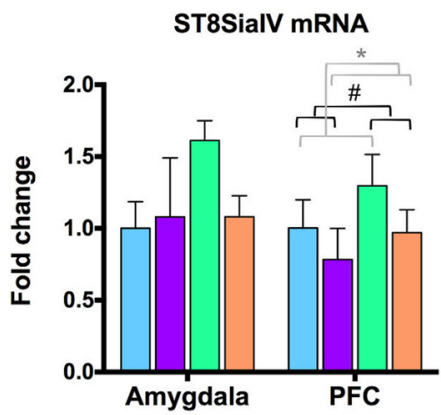

J

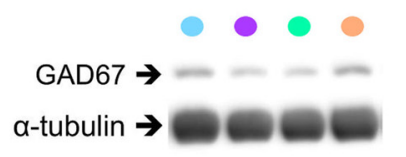

Amygdala

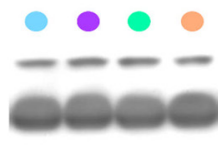

PFC

K

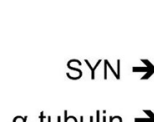

$\alpha$-tubulin $\rightarrow$

\section{$\mathrm{NaCl}-\mathrm{Social}$}

NaCl-Isolation

$\square$ MK801-Social

\section{MK801-Isolation}

Figure 8. Protein and gene expression studies. Bar graphs showing the presence or lack of effect of the treatment, rearing, or their interaction in GAD67, SYN, and PSA-NCAM protein expression (A-C) and in GAD67, BDNF, ErbB4, CB1-R, ST8Siall, and ST8SialV mRNA levels $(\boldsymbol{D}-\boldsymbol{I})$. Horizontal lines in graphs represent trends and statistically significant effects of MK801 treatment (black), rearing (gray) or interaction (gray, dashed) in a two-way ANOVA. \# $0.1>p>0.05, * p<0.05, * * p<0.01, * * * p<0.001 . \boldsymbol{J} \& \boldsymbol{K}$ : Representative bands from immunoblots for GAD67 ( $\boldsymbol{J})$ and SYN $(\boldsymbol{K})$ in the amygdala and the PFC. 
Table 6. Summary of results (part V)

\begin{tabular}{|c|c|c|c|c|c|c|}
\hline \multirow[b]{2}{*}{ Parameter } & \multicolumn{3}{|c|}{ Main effects (two-way ANOVA) } & \multicolumn{3}{|c|}{ Group differences (from NaCl-Social) } \\
\hline & Treatment & Rearing & Interaction & $\mathrm{NaCl}$-Isolation & MK801-Social & MK801-Isolation \\
\hline \multicolumn{7}{|c|}{ PV+ neurons (Fig. 9) } \\
\hline \multicolumn{7}{|l|}{ Amygdala } \\
\hline Total & - & - & $\#^{(110)}$ & $\mathrm{n} / \mathrm{a}$ & $\mathrm{n} / \mathrm{a}$ & $\mathrm{n} / \mathrm{a}$ \\
\hline Central & - & - & - & $\mathrm{n} / \mathrm{a}$ & $\mathrm{n} / \mathrm{a}$ & $\mathrm{n} / \mathrm{a}$ \\
\hline Lateral & - & - & - & $\mathrm{n} / \mathrm{a}$ & $\mathrm{n} / \mathrm{a}$ & $\mathrm{n} / \mathrm{a}$ \\
\hline Basolateral & - & - & $\mathcal{S}^{(111)}$ & - & - & - \\
\hline Basomedial & - & - & $\mathfrak{J}^{(112)}$ & - & - & $\uparrow^{*}$ \\
\hline \multicolumn{7}{|l|}{ PFC } \\
\hline Total & - & - & $\mathcal{S}^{(113)}$ & - & - & - \\
\hline IL & - & $\mathfrak{J}^{(114)}$ & $\mathfrak{J}^{(115)}$ & $\uparrow^{*}$ & $\uparrow^{* * *}$ & - \\
\hline PrL & - & - & $\mathfrak{S}^{(116)}$ & - & - & - \\
\hline \multicolumn{7}{|l|}{ PNNs (Fig. 9) } \\
\hline \multicolumn{7}{|l|}{ Amygdala } \\
\hline Total & $\mathfrak{J}^{(117)}$ & - & $\mathcal{J}^{(118)}$ & - & - & - \\
\hline Central & $\mathcal{J}^{(119)}$ & - & - & $\mathrm{n} / \mathrm{a}$ & $\mathrm{n} / \mathrm{a}$ & $\mathrm{n} / \mathrm{a}$ \\
\hline Lateral & - & - & - & $\mathrm{n} / \mathrm{a}$ & $\mathrm{n} / \mathrm{a}$ & $\mathrm{n} / \mathrm{a}$ \\
\hline Basolateral & $\mathcal{J}^{(120)}$ & - & $\mathfrak{S}^{(121)}$ & - & - & - \\
\hline Basomedial & $\#^{(122)}$ & $\mathfrak{J}^{(123)}$ & - & $\mathrm{n} / \mathrm{a}$ & $\mathrm{n} / \mathrm{a}$ & $\mathrm{n} / \mathrm{a}$ \\
\hline \multicolumn{7}{|l|}{ PFC } \\
\hline Total & - & - & $\mathfrak{S}^{(124)}$ & - & $\uparrow^{* * *}$ & - \\
\hline IL & $\mathfrak{J}^{(125)}$ & $\mathfrak{J}^{(126)}$ & $\mathfrak{S}^{(127)}$ & $\uparrow^{*}$ & $\uparrow^{* * * *}$ & - \\
\hline PrL & - & - & - & $\mathrm{n} / \mathrm{a}$ & $\mathrm{n} / \mathrm{a}$ & $\mathrm{n} / \mathrm{a}$ \\
\hline \multicolumn{7}{|c|}{ PV-PNN colocalization (Fig. 9) } \\
\hline \multicolumn{7}{|l|}{ Amygdala } \\
\hline Total & - & $\mathfrak{J}^{(128)}$ & $\mathcal{S}^{(129)}$ & - & $\uparrow \#$ & - \\
\hline Central & - & - & - & $\mathrm{n} / \mathrm{a}$ & $\mathrm{n} / \mathrm{a}$ & $\mathrm{n} / \mathrm{a}$ \\
\hline Lateral & - & - & - & $\mathrm{n} / \mathrm{a}$ & $n / a$ & $\mathrm{n} / \mathrm{a}$ \\
\hline Basolateral & - & - & $\mathcal{S}^{(130)}$ & - & - & - \\
\hline Basomedial & $\#^{(131)}$ & $\mathfrak{S}^{(132)}$ & - & $\mathrm{n} / \mathrm{a}$ & $\mathrm{n} / \mathrm{a}$ & $\mathrm{n} / \mathrm{a}$ \\
\hline \multicolumn{7}{|l|}{ PFC } \\
\hline Total & - & $\#^{(133)}$ & $\mathfrak{S}^{(134)}$ & - & $\uparrow * *$ & $\downarrow \#$ \\
\hline IL & $\mathfrak{J}^{(135)}$ & $\mathfrak{S}^{(136)}$ & $\mathfrak{S}^{(137)}$ & - & $\uparrow^{* * * *}$ & - \\
\hline PrL & - & - & - & $\mathrm{n} / \mathrm{a}$ & $\mathrm{n} / \mathrm{a}$ & $\mathrm{n} / \mathrm{a}$ \\
\hline
\end{tabular}

Symbols: $(\checkmark)$ statistically significant effect (two-way ANOVA); $(-)$ no statistically significant effect (two-way ANOVA) or difference from NaCl-Social group (post hoc); $(\uparrow$ ) increase; (n/a) not applicable; $(\downarrow)$ decrease; $* p<0.05 ; * * p<0.01 ; * * * p<0.001 ; \# 0.10 \geq p \geq 0.05$.

$F$ values and $p$ values: $(110) F_{(1,21)}=3.99, p=0.059 ;(111) F_{(1,18)}=7.06, p=0.016 ;(112) F_{(1,20)}=4.80, p=0.041 ;(113) F_{(1,14)}=12.82, p=0.003 ;(114)$ $F_{(1,15)}=7.22, p=0.017 ;(115) F_{(1,15)}=52.97, p=3 \times 10^{-6} ;(116) F_{(1,15)}=7.03, p=0.018 ;(117) F_{(1,20)}=5.648, p=0.028 ;(118) F_{(1,20)}=6.70, p=0.016 ;$ $(119) F_{(1,18)}=10.19, p=0.005 ;(120) F_{(1,21)}=4.91, p=0.038 ;(121) F_{(1,21)}=12.96, p=0.002 ;(122) F_{(1,20)}=3.39, p=0.08 ;(123) F_{(1,20)}=6.4, p=0.02 ;$ (124) $F_{(1,14)}=10.55, p=0.006 ;(125) F_{(1,15)}=12.93, p=0.003 ;(126) F_{(1,15)}=17.92, p=0.001 ;(127) F_{(1,15)}=88.68, p<10-7 ;(128) F_{(1,19)}=10.95, p=$ $0.004 ;(129) F_{(1,19)}=13.36, p=0.002 ;(130) F_{(1,19)}=6.53, p=0.019 ;(131) F_{(1,21)}=2.99, p=0.098 ;(132) F_{(1,21)}=4.97, p=0.037 ;(133) F_{(1.13)}=3.61$, $p=0.08 ;(134) F_{(1,13)}=15.49, p=0.002 ;(135) F_{(1,15)}=19.87, p=4.61 \times 10^{-4} ;(136) F_{(1,15)}=47.52, p=5 \times 10^{-6} ;(137) F_{(1,15)}=87.65, p<10^{-7}$.

working memory abnormalities after these treatments (Andersen and Pouzet, 2004; Bubeníková-Valesová et al. 2008; Belforte et al. 2010; Nozari et al. 2015), others failed to find them (Bubeníková-Valesová et al. 2008; Rompala et al. 2013).

\section{Changes in Brain Volume and Neuronal Structure}

Numerous studies in humans and animal models of schizophrenia have documented the presence of structural alterations in the BLA and PFC, including volume impairments (Jaaro-Peled et al. 2010; Levitt et al. 2010). Early-life stress also has dramatic effects on brain structure, especially on the amygdala (hypertrophy, increased activity, and dendritic arborization of excitatory neurons; for review, see Coplan et al. 2014). In our study, early-life stress, but not specifically the double-hit model, has a negative effect in the volume of the PFC (as described previously in rats, Gilabert-Juan et al. 2013a), but increases the volume of CeA. To our knowledge, there are no previous studies on the effects of social isolation rearing on these nuclei, although reductions in the volume of the MeA have been described (Cooke et al. 2000).

As these volumetric alterations may probably reflect structural changes in PFC and BLA neurons, we decided to analyze their structure. In fact, a previous Golgi study in rats found that social isolation rearing reduces the length of dendritic segments of pyramidal neurons in the BLA while increasing their complexity (Wang et al. 2012). This study also found reduced dendritic arborization and spine density in mPFC pyramidal neurons, similar to what has been found after chronic stress in adult rats (Radley et al. 2004, 2006). By contrast, also with data from schizophrenic patients and rat models (Jones et al. 2011; Flores et al. 2016), we have not observed a significant reduction in spine density of the PFC pyramidal neurons in isolated or double-hit mice. This controversy could be due to species differences. However, because there is a clear trend toward a decrease in the double-hit animals, it is 
A
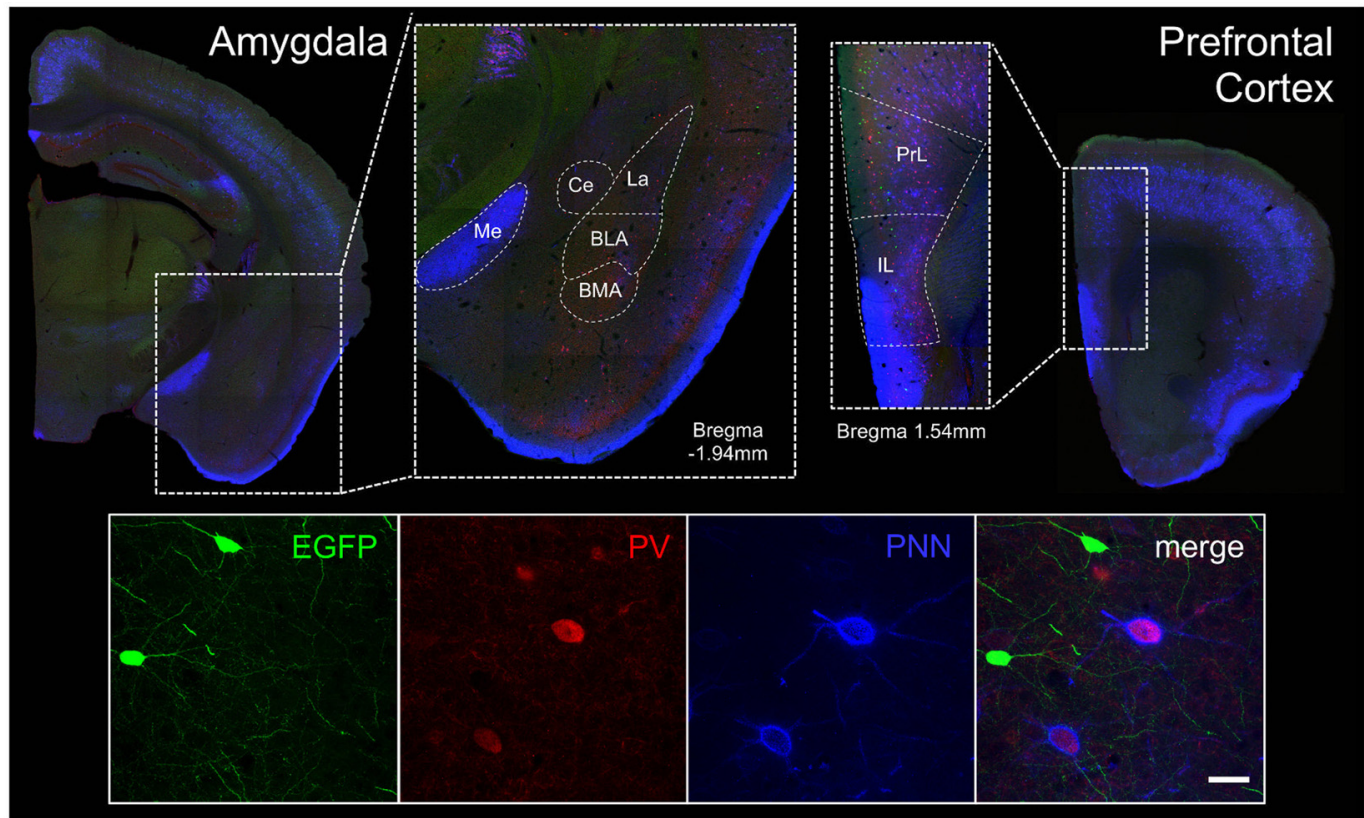

B1

Amygdala

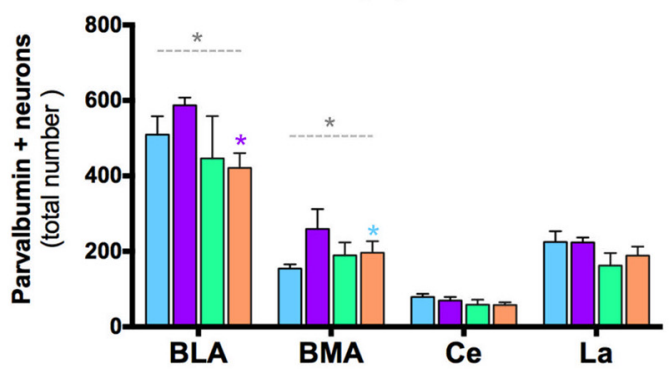

B2

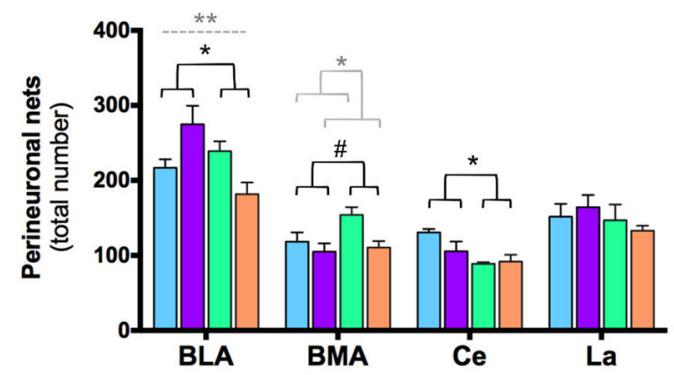

B3

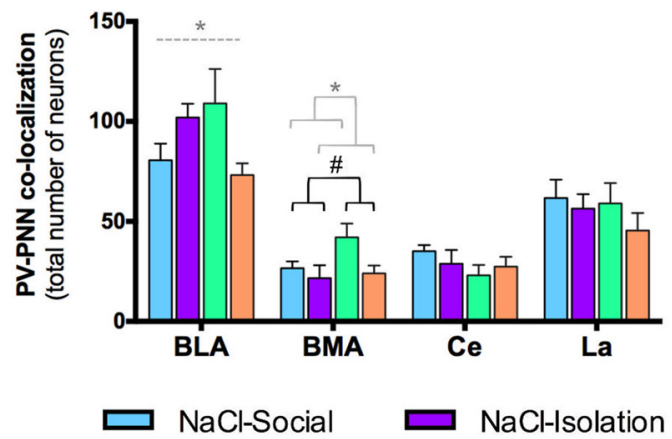

C1
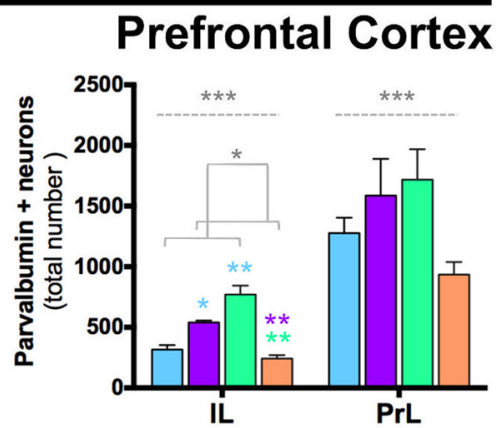

C2

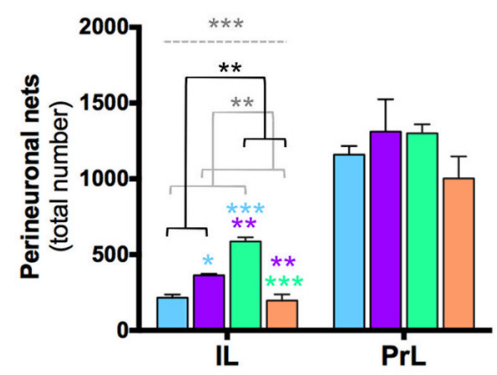

C3

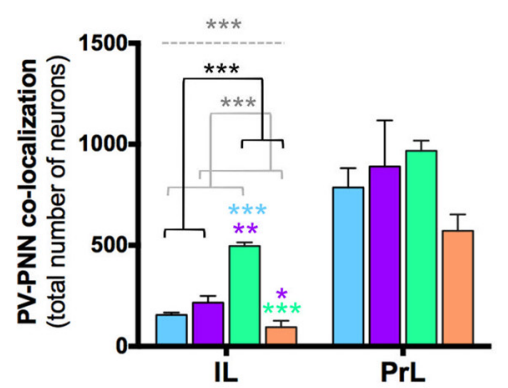

MK801-Social

MK801-Isolation

Figure 9. Expression of PNNs in PV-immunoreactive neurons. A, Representative confocal images showing the distribution of PV (red) and PNNs (blue) in the different nuclei of the amygdala (left) and regions of the PFC (right) of GIN mice (GAD-GFP, green). The squared 
continued

section in the panoramic images was $2 \times$ magnified to show the different nuclei and areas that were analyzed. In a detailed view (below), two PV-immunoreactive neurons expressing PNN can be observed. GAD-GFP expressing interneurons do not express PNN. Scale bars: panoramic views, $875 \mu \mathrm{m}$; detailed view, $25 \mu \mathrm{m}$. $\boldsymbol{B}, \boldsymbol{C}$, Treatment, rearing, or their interaction affected the total number of PV neurons $(\mathbf{B 1}, \mathbf{C} 1)$, PNNs $(\mathbf{B 2}, \mathbf{C 2})$, or their colocalization $(\mathbf{B 3}, \mathbf{C} 3)$ in some nuclei of the amygdala and regions of the PFC. Horizontal lines in graphs represent trends and statistically significant effects of MK801 treatment (black), rearing (gray), or interaction (gray, dashed) in a two-way ANOVA. \# $0.1>p>0.05, * p<0.05, * * p<0.01, * * * p<0.001$. Colored symbols in bars represent trends and statistically significant differences among groups after post hoc analysis: \# $0.1>p>0.05, * p<0.05, * * p<0.01, * * * p<0.001$.

possible that studies with higher number of animals would render significant results on this parameter.

An increase in dendritic spine density was found in PFC interneurons of isolated and double-hit mice, which may lead to an increased number of synaptic contacts on these interneurons. Future experiments should explore whether these new spines are active and receive excitatory and/or inhibitory contacts. We have also detected a significant increase in dendritic arborization in amygdaloid interneurons of the double-hit mice, also suggesting an increased surface for the reception of new synaptic contacts. Interestingly, the subpopulation of interneurons studied in the present paper, which mainly express somatostatin (Oliva et al. 2000), also exhibits hypertrophic changes when young adult mice are subjected to chronic stress (Gilabert-Juan et al. 2011, 2013b). These findings are especially relevant because, despite the abundant number of studies that point to interneurons as key players in neurodevelopmental mental disorders, no studies looking for dendritic abnormalities in interneurons, neither of the PFC nor the amygdala, have been conducted before.

\section{Alterations in Structural Plasticity and E/I Neurotransmission}

The impairments in the morphology and connectivity of neurons may be mediated by changes in the expression of the plasticity-related molecule PSA-NCAM (Bonfanti, 2006; Rutishauser, 2008; Nacher et al. 2013). Postweaning social isolation rearing in rats leads to increases in the expression of PSA-NCAM during adulthood, specially in the basolateral amygdaloid nucleus (GilabertJuan et al. 2012). Adult rats exposed to different physical stressors during adolescence show a similar increase in this nucleus (Tsoory et al. 2008). However, in the present experiment, both the isolated and the double-hit mice showed decreased expression of PSA-NCAM in the amygdala in adult life. These apparently contradictory results could be due to species differences and/or to a different impact of stress in different amygdaloid regions, because the expression of PSA-NCAM in the present study has been studied in the whole amygdala. In fact, similar reductions in the expression of this molecule have been found after chronic stress in the central amygdala of adult mice (Gilabert-Juan et al. 2011) and rats (Cordero et al. 2005). These findings are specially relevant for inhibitory circuits, because in the amygdala and PFC, PSANCAM is exclusively expressed by interneurons, and therefore is able to regulate directly its structure and connectivity (Nacher et al. 2013).
PNNs were reduced in the lateral nucleus of the amygdala (Pantazopoulos et al. 2010) and the PFC in schizophrenic patients (Mauney et al. 2013). Reduced labeling of PV neurons was also observed in these patients (Enwright et al. 2016). Moreover, a recent report has described a disruption of PNNs in the mPFC after in an animal model of this disorder (maternal immune activation; Paylor et al. 2016). Our study also reveals a similar, although nonsignificant, decrease in these parameters in the infralimbic cortex of the double-hit mice. This is in accordance with previous results on PV-expressing neurons in this prefrontocortical region using the same double-hit model in rats (Gilabert-Juan et al. 2013a). However, it has to be noted that opposite effects were observed in the MK-801 group of animals. We do not have an explanation yet for these effects and there are no previous studies looking at the effects of NMDAR antagonists on PNNs.

The precise balance between excitatory and inhibitory neurotransmission is crucial for the proper maturation of the neural circuitry during development. In fact, E/I imbalances in key brain regions have been proposed as underlying causes of some neurodevelopmental psychiatric disorders, including schizophrenia (Curley and Lewis, 2012; Lewis et al. 2012; Inan et al. 2013; Lin et al. 2013; Sun et al. 2013; Morishita et al. 2015). Our data support this hypothesis, demonstrating that early-life stress strongly influences E/I balance and that alterations in this balance are particularly evident in the PFC and the amygdala of double-hit mice. E/I balance can also be affected by changes in the expression of other molecules that influence the maturation of inhibitory circuits and that have also been related to schizophrenia. This is the case of BDNF (Sánchez-Huertas and Rico, 2011), ST8SialV (Nacher et al. 2010), and CB1-R (Volk and Lewis, 2010; den Boon et al. 2015). BDNF and ST8SialV mRNA levels in the PFC are increased and decreased, respectively, by early-life stress, whereas CB1-R mRNA levels in the amygdala are increased.

\section{Concluding remarks and future perspectives}

The present results suggest an important impact of stressful events in early life on inhibitory networks, both at the structural and the neurochemical level. We still do not know whether the changes in the structure (and probably in the connectivity) of interneurons precede or are the response to alterations in the excitatory neurotransmission. Future experiments evaluating different time points should clarify this matter. The present model may constitute a powerful resource for the study of the influence of early-life aversive experiences on the adult brain and to deepen further in the understanding of the neurobiological 
basis of mental disorders in which these experiences seem to play a critical role, such as schizophrenia. The model may constitute an interesting tool for testing new antipsychotic drugs or to understand how other genetic or environmental factors, particularly during the early-life stages, can impact on the development of this symptomatology. Future studies will have to expand the battery of behavioral tests, particularly those measuring prefrontaland amygdaloid-related behaviors. Given the alterations found in the structure of interneurons and in some molecules related to inhibitory neurotransmission, it would also be interesting to analyze them in more detail.

\section{References}

Akbarian S (1995) Gene expression for glutamic acid decarboxylase is reduced without loss of neurons in prefrontal cortex of schizophrenics. Arch Gen Psychiatry 52:258. Medline

Akbarian S, Huang HS (2006) Molecular and cellular mechanisms of altered GAD1/GAD67 expression in schizophrenia and related disorders. Brain Res Rev 52:293-304. CrossRef Medline

Andersen JD, Pouzet B (2004) Spatial memory deficits induced by perinatal treatment of rats with PCP and reversal effect of D-serine. Neuropsychopharmacology 29:1080-1090. CrossRef Medline

Belforte JE, Zsiros V, Sklar ER, Jiang Z, Yu G, Li Y, Quinlan EM, Nakazawa K (2010) Postnatal NMDA receptor ablation in corticolimbic interneurons confers schizophrenia-like phenotypes. Nat Neurosci 13:76-83. CrossRef Medline

Berretta S, Pantazopoulos H, Markota M, Brown C, Batzianouli ET (2015) Losing the sugar coating: Potential impact of perineuronal net abnormalities on interneurons in schizophrenia. Schizophr Res 167:18-27. CrossRef Medline

Bonefeld BE, Elfving B, Wegener G (2008) Reference genes for normalization: a study of rat brain tissue. Synapse 62:302-309. CrossRef Medline

Bonfanti L (2006) PSA-NCAM in mammalian structural plasticity and neurogenesis. Prog Neurobiol 80:129-164. CrossRef Medline

Bubeníková-Valesová V, Horácek J, Vrajová M, Höschl C (2008) Models of schizophrenia in humans and animals based on inhibition of NMDA receptors. Neurosci Biobehav Rev 32:1014-1023. CrossRef Medline

Castilla-Ortega E, Sánchez-López J, Hoyo-Becerra C, Matas-Rico E, Zambrana-Infantes E, Chun J, De Fonseca FR, Pedraza C, EstivillTorrús G, Santin LJ (2010) Exploratory, anxiety and spatial memory impairments are dissociated in mice lacking the LPA1 receptor. Neurobiol Learn Mem 94:73-82. CrossRef Medline

Cooke BM, Chowanadisai W, Breedlove SM (2000) Post-weaning social isolation of male rats reduces the volume of the medial amygdala and leads to deficits in adult sexual behavior. Behav Brain Res 117:107-113. Medline

Coplan JD, Fathy HM, Jackowski AP, Tang CY, Perera TD, Mathew SJ, Martinez J, Abdallah CG, Dwork AJ, Pantol G, Carpenter D, Gorman JM, Nemeroff CB, Owens MJ, Kaffman A, Kaufman J (2014) Early life stress and macaque amygdala hypertrophy: preliminary evidence for a role for the serotonin transporter gene. Front Behav Neurosci 8:342. CrossRef Medline

Cordero MI, Rodríguez JJ, Davies HA, Peddie CJ, Sandi C, Stewart MG (2005) Chronic restraint stress down-regulates amygdaloid expression of polysialylated neural cell adhesion molecule. Neuroscience 133:903-910. CrossRef Medline

Curley AA, Lewis DA (2012) Cortical basket cell dysfunction in schizophrenia. J Physiol 590:715-724. CrossRef Medline

den Boon FS, Werkman TR, Schaafsma-Zhao Q, Houthuijs K, Vitalis T, Kruse CG, Wadman WJ, Chameau P (2015) Activation of type-1 cannabinoid receptor shifts the balance between excitation and inhibition towards excitation in layer II/III pyramidal neurons of the rat prelimbic cortex. PflüGers Arch 467:1551-1564. CrossRef
Duman $\mathrm{CH}$, Duman RS (2015) Spine synapse remodeling in the pathophysiology and treatment of depression. Neurosci Lett601: 20-29. CrossRef

Enwright JF, Sanapala S, Foglio A, Berry R, Fish KN, Lewis DA (2016) Reduced labeling of parvalbumin neurons and perineuronal nets in the dorsolateral prefrontal cortex of subjects with schizophrenia. Neuropsychopharmacology 41:2206-2214. CrossRef Medline

Feng G, Mellor RH, Bernstein M, Keller-Peck C, Nguyen QT, Wallace M, Nerbonne JM, Lichtman JW, Sanes JR (2000) Imaging neuronal subsets in transgenic mice expressing multiple spectral variants of GFP. Neuron 28:41-51. Medline

Ferdman N, Murmu RP, Bock J, Braun K, Leshem M (2007) Weaning age, social isolation, and gender, interact to determine adult explorative and social behavior, and dendritic and spine morphology in prefrontal cortex of rats. Behav Brain Res 180:174-182. CrossRef Medline

Flores G, Morales-Medina JC, Diaz A (2016) Neuronal and brain morphological changes in animal models of schizophrenia. Behav Brain Res 301:190-203. CrossRef Medline

Geyer MA, Wilkinson LS, Humby T, Robbins TW (1993) Isolation rearing of rats produces a deficit in prepulse inhibition of acoustic startle similar to that in schizophrenia. Biol Psychiatry 34:361-372. Medline

Gilabert-Juan J, Belles M, Saez AR, Carceller H, Zamarbide-Fores S, Moltó MD, Nacher J (2013a) A "double hit" murine model for schizophrenia shows alterations in the structure and neurochemistry of the medial prefrontal cortex and the hippocampus. Neurobiol Dis 59:126-140.

Gilabert-Juan J, Castillo-Gomez E, Guirado R, Moltó MD, Nacher J (2013b) Chronic stress alters inhibitory networks in the medial prefrontal cortex of adult mice. Brain Struct Funct 218:1591-1605.

Gilabert-Juan J, Castillo-Gomez E, Pérez-Rando M, Moltó MD, Nacher J (2011) Chronic stress induces changes in the structure of interneurons and in the expression of molecules related to neuronal structural plasticity and inhibitory neurotransmission in the amygdala of adult mice. Exp Neurol 232:33-40. CrossRef Medline

Gilabert-Juan J, Moltó MD, Nacher J (2012) Post-weaning social isolation rearing influences the expression of molecules related to inhibitory neurotransmission and structural plasticity in the amygdala of adult rats. Brain Res 1448:129-136. CrossRef Medline

Glausier JR, Lewis DA (2013) Dendritic spine pathology in schizophrenia. Neuroscience 251:90-107. CrossRef Medline

Goghari VM, Sponheim SR, MacDonald AW (2010) The functional neuroanatomy of symptom dimensions in schizophrenia: a qualitative and quantitative review of a persistent question. Neurosci Biobehav Rev 34:468-486. CrossRef Medline

Guirado R, Sanchez-Matarredona D, Varea E, Crespo C, BlascoIbáñez JM, Nacher J (2012) Chronic fluoxetine treatment in middle-aged rats induces changes in the expression of plasticityrelated molecules and in neurogenesis. BMC Neurosci 13:5. CrossRef Medline

Gundersen HJ, Jensen EB (1987) The efficiency of systematic sampling in stereology and its prediction. J Microsc 147:229-263. Medline

Härtig W, Brauer K, Brückner G (1992) Wisteria floribunda agglutininlabelled nets surround parvalbumin-containing neurons. Neuroreport 3:869-872. Medline

Hickey AJ, Reynolds JN, Beninger RJ (2012) Post-weaning social isolation and subchronic NMDA glutamate receptor blockade: effects on locomotor activity and GABA signaling in the rat suggest independent mechanisms. Pharmacol Biochem Behav 101:231238. CrossRef Medline

Ikonomidou C, Bosch F, Miksa M, Bittigau P, Vöckler J, Dikranian K, Tenkova TI, Stefovska V, Turski L, Olney JW (1999) Blockade of NMDA receptors and apoptotic neurodegeneration in the developing brain. Science 283:70-74. Medline

Inan M, Petros TJ, Anderson SA (2013) Losing your inhibition: linking cortical GABAergic interneurons to schizophrenia. Neurobiol Dis 53:36-48. CrossRef Medline 
Jaaro-Peled H, Ayhan Y, Pletnikov MV, Sawa A (2010) Review of pathological hallmarks of schizophrenia: comparison of genetic models with patients and nongenetic models. Schizophr Bull 36: 301-313. CrossRef Medline

Jansson LC, Åkerman KE (2014) The role of glutamate and its receptors in the proliferation, migration, differentiation and survival of neural progenitor cells. J Neural Transm 121:819-836. CrossRef Medline

Jiang Z, Rompala GR, Zhang S, Cowell RM, Nakazawa K (2013) Social isolation exacerbates schizophrenia-like phenotypes via oxidative stress in cortical interneurons. Biol Psychiatry 73:10241034. CrossRef Medline

Jones CA, Watson DJ, Fone KC (2011) Animal models of schizophrenia. Br J Pharmacol 164:1162-1194. CrossRef Medline

Karl T, Duffy L, Herzog H (2008) Behavioural profile of a new mouse model for NPY deficiency. Eur J Neurosci 28:173-180. CrossRef Medline

Kinden Lensjø K, Elle Lepperød M, Dick G, Hafting T, Fyhn M (2017) Removal of perineuronal nets unlocks juvenile plasticity through network mechanisms of decreased inhibition and increased gamma activity. J Neurosci 37:1269-1283.

Koike H, Ibi D, Mizoguchi H, Nagai T, Nitta A, Takuma K, Nabeshima T, Yoneda Y, Yamada K (2009) Behavioral abnormality and pharmacologic response in social isolation-reared mice. Behav Brain Res 202:114-121. CrossRef Medline

Lett TA, Voineskos AN, Kennedy JL, Levine B, Daskalakis ZJ (2014) Treating working memory deficits in schizophrenia: a review of the neurobiology. Biol Psychiatry 75:361-370. CrossRef Medline

Levitt JJ, Bobrow L, Lucia D, Srinivasan P (2010) A selective review of volumetric and morphometric imaging in schizophrenia. Curr Top Behav Neurosci 4:243-281. Medline

Lewis DA, Curley AA, Glausier JR, Volk DW (2012) Cortical parvalbumin interneurons and cognitive dysfunction in schizophrenia. Trends Neurosci 35:57-67. CrossRef Medline

Lim AL, Taylor DA, Malone DT (2012) A two-hit model: behavioural investigation of the effect of combined neonatal MK-801 administration and isolation rearing in the rat. J Psychopharmacol 26: 1252-1264. CrossRef Medline

Lin HC, Gean PW, Wang CC, Chan YH, Chen PS (2013) The amygdala excitatory/inhibitory balance in a valproate-induced rat autism model. PLoS One 8:e55248. CrossRef Medline

Longair MH, Baker DA, Armstrong JD (2011) Simple Neurite Tracer: open source software for reconstruction, visualization and analysis of neuronal processes. Bioinformatics 27:2453-2454. CrossRef Medline

Lyall A, Swanson J, Liu C, Blumenthal TD, Turner CP (2009) Neonatal exposure to MK801 promotes prepulse-induced delay in startle response time in adult rats. Exp Brain Res 197:215-222. CrossRef Medline

Mauney SA, Athanas KM, Pantazopoulos H, Shaskan N, Passeri E, Berretta S, Woo TU (2013) Developmental pattern of perineuronal nets in the human prefrontal cortex and their deficit in schizophrenia. Biol Psychiatry 74:427-435. CrossRef Medline

Mitchell AC, Jiang Y, Peter C, Akbarian S (2015) Transcriptional regulation of GAD1 GABA synthesis gene in the prefrontal cortex of subjects with schizophrenia. Schizophr Res 167:28-34. CrossRef Medline

Morishita H, Kundakovic M, Bicks L, Mitchell A, Akbarian S (2015) Interneuron epigenomes during the critical period of cortical plasticity: Implications for schizophrenia. Neurobiol Learn Mem 124: 104-110. CrossRef Medline

Nacher J, Alonso-Llosa G, Rosell D, McEwen B (2002) PSA-NCAM expression in the piriform cortex of the adult rat: modulation by NMDA receptor antagonist administration. Brain Res 927:111121. Medline

Nacher J, Guirado R, Castillo-Gómez E (2013) Structural plasticity of interneurons in the adult brain: role of PSA-NCAM and implications for psychiatric disorders. Neurochem Res 38:1122-1133.

Nacher J, Guirado R, Varea E, Alonso-Llosa G, Röckle I, Hildebrandt H (2010) Divergent impact of the polysialyltransferases ST8Siall and ST8SialV on polysialic acid expression in immature neurons and interneurons of the adult cerebral cortex. Neuroscience 167: 825-837. CrossRef Medline

Nozari M, Mansouri FA, Shabani M, Nozari H, Atapour N (2015) Postnatal MK-801 treatment of female rats impairs acquisition of working memory, but not reference memory in an eight-arm radial maze; no beneficial effects of enriched environment. Psychopharmacology (Berl) 232:2541-2550. CrossRef Medline

Oliva AA, Jiang M, Lam T, Smith KL, Swann JW (2000) Novel hippocampal interneuronal subtypes identified using transgenic mice that express green fluorescent protein in GABAergic interneurons. J Neurosci 20:3354-3368. Medline

Pallanti S, Cantisani A, Grassi G (2013) Anxiety as a core aspect of schizophrenia. Curr Psychiatry Rep 15:354. CrossRef Medline

Pallanti S, Salerno L (2015) Raising attention to attention deficit hyperactivity disorder in schizophrenia. World J Psychiatry 5:4755. CrossRef Medline

Pantazopoulos H, Woo TU, Lim MP, Lange N, Berretta S (2010) Extracellular matrix-glial abnormalities in the amygdala and entorhinal cortex of subjects diagnosed with schizophrenia. Arch Gen Psychiatry 67:155. CrossRef Medline

Paylor JW, Lins BR, Greba Q, Moen N, de Moraes RS, Howland JG, Winship IR (2016) Developmental disruption of perineuronal nets in the medial prefrontal cortex after maternal immune activation. Sci Rep 6:37580. CrossRef Medline

Pfaffl MW (2001) A new mathematical model for relative quantification in real-time RT-PCR. Nucleic Acids Res 29:e45. Medline

Porrero C, Rubio-Garrido P, Avendaño C, Clascá F (2010) Mapping of fluorescent protein-expressing neurons and axon pathways in adult and developing Thy1-eYFP-H transgenic mice. Brain Res 1345:59-72. CrossRef Medline

Radley JJ, Rocher AB, Miller M, Janssen WGM, Liston C, Hof PR, McEwen BS, Morrison JH (2006) Repeated stress induces dendritic spine loss in the rat medial prefrontal cortex. Cereb Cortex 16:313-320. CrossRef

Radley JJ, Sisti HM, Hao J, Rocher AB, McCall T, Hof PR, McEwen BS, Morrison JH (2004) Chronic behavioral stress induces apical dendritic reorganization in pyramidal neurons of the medial prefrontal cortex. Neuroscience 125:1-6. CrossRef Medline

Rico B, Marín O (2011) Neuregulin signaling, cortical circuitry development and schizophrenia. Curr Opin Genet Dev 21:262-270. CrossRef Medline

Rompala GR, Zsiros V, Zhang S, Kolata SM, Nakazawa K (2013) Contribution of NMDA receptor hypofunction in prefrontal and cortical excitatory neurons to schizophrenia-like phenotypes. PLoS One 8:e61278. CrossRef Medline

Rutishauser U (2008) Polysialic acid in the plasticity of the developing and adult vertebrate nervous system. Nat Rev Neurosci 9:26-35. CrossRef Medline

Saaltink DJ, Vreugdenhil E (2014) Stress, glucocorticoid receptors, and adult neurogenesis: a balance between excitation and inhibition?. Cell Mol Life Sci 71:2499-2515. CrossRef Medline

Sánchez-Huertas C, Rico B (2011) CREB-dependent regulation of GAD65 transcription by BDNF/TrkB in cortical interneurons. Cereb Cortex 21:777-788. CrossRef Medline

Sandi C (2004) Stress, cognitive impairment and cell adhesion molecules. Nat Rev Neurosci 5:917-930. CrossRef Medline

Schindelin J, Arganda-Carreras I, Frise E, Kaynig V, Longair M, Pietzsch T, Preibisch S, Rueden C, Saalfeld S, Schmid B, Tinevez JY, White DJ, Hartenstein V, Eliceiri K, Tomancak P, Cardona A (2012) Fiji: an open-source platform for biological-image analysis. Nat Methods 9:676-682. CrossRef Medline

Simon P, Dupuis R, Costentin J (1994) Thigmotaxis as an index of anxiety in mice. Influence of dopaminergic transmissions. Behav Brain Res 61:59-64. Medline

Straub RE, Lipska BK, Egan MF, Goldberg TE, Callicott JH, Mayhew MB, Vakkalanka RK, Kolachana BS, Kleinman JE, Weinberger DR (2007) Allelic variation in GAD1 (GAD67) is associated with schizophrenia and influences cortical function and gene expression. Mol Psychiatry 12:854-869. CrossRef Medline 
Sun L, Castellanos N, Grützner C, Koethe D, Rivolta D, Wibral M, Kranaster L, Singer W, Leweke MF, Uhlhaas PJ (2013) Evidence for dysregulated high-frequency oscillations during sensory processing in medication-naïve, first episode schizophrenia. Schizophr Res 150:519-525. CrossRef Medline

Tao HW, Li Y, Zhang LI (2014) Formation of excitation-inhibition balance: inhibition listens and changes its tune. Trends Neurosci 37:528-530. CrossRef Medline

Torres-García ME, Solis O, Patricio A, Rodríguez-Moreno A, Camacho-Abrego I, Limón ID, Flores G (2012) Dendritic morphology changes in neurons from the prefrontal cortex, hippocampus and nucleus accumbens in rats after lesion of the thalamic reticular nucleus. Neuroscience 223:429-438. CrossRef Medline

Tsoory M, Guterman A, Richter-Levin G (2008) Exposure to stressors during juvenility disrupts development-related alterations in the PSA-NCAM to NCAM expression ratio: potential relevance for mood and anxiety disorders. Neuropsychopharmacology 33:378393. CrossRef Medline

Tzanoulinou S, Riccio O, de Boer MW, Sandi C (2014) Peripubertal stress-induced behavioral changes are associated with altered expression of genes involved in excitation and inhibition in the amygdala. Transl Psychiatry 4:e410. CrossRef Medline

van der Kooij MA, Fantin M, Kraev I, Korshunova I, Grosse J, Zanoletti O, Guirado R, Garcia-Mompó C, Nacher J, Stewart MG, Berezin V, Sandi C (2014) Impaired hippocampal neuroligin-2 function by chronic stress or synthetic peptide treatment is linked to social deficits and increased aggression. Neuropsychopharmacology 39:1148-1158. CrossRef Medline

Van Snellenberg JX, Girgis RR, Horga G, van de Giessen E, Slifstein M, Ojeil N, Weinstein JJ, Moore H, Lieberman JA, Shohamy D, Smith EE, Abi-Dargham A (2016) Mechanisms of working memory impairment in schizophrenia. Biol Psychiatry 80:617-626.

Volk DW, Lewis DA (2010) Prefrontal cortical circuits in schizophrenia. Curr Top Behav Neurosci 4:485-508. Medline

Wang CZ, Johnson KM (2005) Differential effects of acute and subchronic administration on phencyclidine-induced neurodegeneration in the perinatal rat. J Neurosci Res 81:284-292. CrossRef

Wang YC, Ho UC, Ko MC, Liao CC, Lee LJ (2012) Differential neuronal changes in medial prefrontal cortex, basolateral amygdala and nucleus accumbens after postweaning social isolation. Brain Struct Funct 217:337-351. CrossRef Medline

Weickert CS, Hyde TM, Lipska BK, Herman MM, Weinberger DR, Kleinman JE (2003) Reduced brain-derived neurotrophic factor in prefrontal cortex of patients with schizophrenia. Mol Psychiatry 8:592-610. CrossRef Medline

Weickert CS, Ligons DL, Romanczyk T, Ungaro G, Hyde TM, Herman MM, Weinberger DR, Kleinman JE (2005) Reductions in neurotrophin receptor mRNAs in the prefrontal cortex of patients with schizophrenia. Mol Psychiatry 10:637-650. CrossRef Medline

West MJ (1993) New stereological methods for counting neurons. Neurobiol Aging 14:275-285. Medline 